\title{
Article \\ Smart Systems and Collaborative Innovation Networks for Productivity Improvement in SMEs
}

\author{
Andrew Thomas ${ }^{1, *(\mathbb{D}}$, Wyn Morris ${ }^{1}\left(\mathbb{D}\right.$, Claire Haven-Tang ${ }^{2}\left(\mathbb{D}\right.$, Mark Francis $^{2}{ }^{(D}$ and Paul Byard $^{3}$ \\ 1 Aberystwyth Business School, Aberystwyth University, Aberystwyth SY23 3FL, UK; dmm@aber.ac.uk \\ 2 Cardiff School of Management, Cardiff Metropolitan University, Cardiff CF5 2YB, UK; \\ chaven-tang@cardiffmet.ac.uk (C.H.-T.); mfrancis@cardiffmet.ac.uk (M.F.) \\ $3 \quad$ FSG Tool and Die Ltd., Pontyclun CF72 8LF, UK; paul.byard@fsgtoolanddie.co.uk \\ * Correspondence: ant42@aber.ac.uk
}

Citation: Thomas, A.; Morris, W.; Haven-Tang, C.; Francis, M.; Byard, P. Smart Systems and Collaborative Innovation Networks for Productivity Improvement in SMEs. J. Open Innov. Technol. Mark. Complex. 2021, 7, 3. https://doi.org/10.3390/joitmc7010003

Received: 17 November 2020 Accepted: 19 December 2020 Published: 23 December 2020

Publisher's Note: MDPI stays neutral with regard to jurisdictional claims in published maps and institutional affiliations.

Copyright: (C) 2020 by the authors. Licensee MDPI, Basel, Switzerland. This article is an open access article distributed under the terms and conditions of the Creative Commons Attribution (CC BY) license (https: / / creativecommons.org/ licenses/by/4.0/).

\begin{abstract}
The adoption of Smart Manufacturing Systems in manufacturing companies is often seen as a strategy towards achieving improvements in productivity. However, there is little evidence to indicate that UK manufacturing SMEs are prepared for the implementation of such systems. Through the employment of a triangulation research approach involving the detailed examination of $36 \mathrm{UK}$ manufacturing SMEs from three manufacturing sectors, this study investigates the level of awareness and understanding within SMEs of Smart Manufacturing Systems. The development of a profiling tool is shown and is subsequently used to audit company awareness and understanding of the key technologies, collaborative networks and systems of SMS. Further information obtained from semi-structured interviews and observations of manufacturing operations provide further contextual information. The findings indicate that whilst the priority technologies and systems differ between manufacturing sectors, the key issues around the need for developing appropriate collaborative networks and knowledge management systems are common to all sectors.
\end{abstract}

Keywords: manufacturing; productivity profile; Smart Manufacturing Systems; survey

\section{Introduction}

The dynamic nature of the UK manufacturing industry requires companies (particularly SMEs) to continually adapt and become more technologically advanced and innovative in terms of their products and processes. Shorter life cycle products, increasingly complex customer requirements, increased legislation and regulation have all resulted in a requirement for organisations to respond on a number of different fronts and on a range of different issues in order to achieve greater productivity [1,2]. As these new demands and drivers take effect, many SMEs, are becoming increasingly isolated from new manufacturing trends and systems [3]. Companies have focused and deployed their resources on current manufacturing issues rather than developing longer term collaborative environments and strategies to deal with the effective implementation and application of new manufacturing technologies and systems [3,4]. The resulting problem of isolation for manufacturing SMEs is that they are not necessarily aware of the advances in manufacturing technologies that are being developed and implemented in the wider manufacturing industry. This in turn, can lead to the creation of an environment where smaller manufacturing companies may become uncompetitive when it comes to adopting and realizing the benefits from new and advanced manufacturing systems and technologies [3,5].

In order to meet these production challenges, some manufacturing sectors have placed an increasing focus upon the development and advancement of technology-driven manufacturing systems, such as Smart Factories, Smart Manufacturing Systems, and Industry 4.0 [5]. However, these developments are located primarily within larger SMEs [6]. Smart Manufacturing Systems (SMS) can be defined as a set of manufacturing practices that use networked data and information and communication technologies (ICTs) for governing 
manufacturing operations [7]. Trends suggest that in the future, SMS will possess unique properties of self-assembly to produce complex and customized products to exploit new and existing markets including the use of data to continuously maintain and improve performance [8]. Over recent years, we have witnessed significant developments in terms of Smart Manufacturing Systems capability, a reduction in the cost of technology, and wider accessibility and availability of the technologies. However, what is unclear is whether manufacturing SMEs are fully aware of such systems and whether they understand the impact that SMS can have on their productivity and manufacturing capability. Therefore, the aim of this study is to gain a greater understanding of the level of awareness and expertise of UK manufacturing SMEs towards the implementation SMS into their companies. In order to guide the SMEs towards a focused discussion around SMS implementation, the authors developed an SMS profiling tool that was created from a comprehensive literature study into SMS technologies and systems and then applied to 36 UK manufacturing SMEs from three manufacturing sectors (mechanical, food and electronics). The tool was used to obtain high-level profiles of the sector's awareness and gain an understanding of the capabilities of SMS.

\section{Literature Review}

UK manufacturing SMEs are aware of the need to continually innovate in order to remain competitive. Smart Manufacturing Systems provide an essential link in that these technologies and systems allow for improved levels of performance and response to customer needs. SMS embrace a wide range of technologies, some of which are identified in Table 1 of this study. SMS technologies offer many benefits that link to the key productivity dimensions, including the ability to improve product traceability [9], reduce production and product waste and increase efficiencies in the transport and handling of products. This in turn contributes directly to addressing the increased challenges that SMEs face in remaining sustainable in all its dimensions [10]. However, as previously discussed, it is not clear whether manufacturing SMEs are currently fully aware of the technologies, systems and the infrastructural requirements of such systems and how these may be employed in their respective companies. In order to address these specific issues, a literature review was undertaken that identifies some of the key enabling technologies as well as some of the systems and management processes required to provide an integrated systems approach to productivity improvement. 
Table 1. An analysis of the literature on smart technologies and management systems.

Thematic Areas

Area 1-Applications and Performance

Area 2-Management Systems

\section{SMS Technologies and Systems}

Three-dimensional (3D) Printing, simulation, virtual reality (VR), Customer integration, virtualization and virtual prototyping (Verdouw et al. 2016; Pusavec et al. 2010), Rapid tooling and Time Compression (Fleith de Medeiros, 2016), Moeuf et al., (2020), Digital Twins Damjanovic-Behrendt andBehrendt (2019), Ding et al. 2019. Cross company collaboration in (Smart Manufacturing Systems (SMS) environments (Warwick Manufacturing Group, 2017); collaborative design environments, (ElMaraghy, 2009), Intelligent product design (Vezzoli, 2003; Jasiulexicz-Kaczmarek andand Saniuk 2015); virtualization and virtual prototyping (Verdouw et al. 2016; Pusavec et al. (2010), Innovation Readiness Models for Smart Systems (Javahernia and Sunmola, 2017). Big Data/Smart Systems connectivity (Caputo, 2019), Inter-functional collaboration, innovation-oriented learning, research and development investment (Jasiulexicz-Kaczmarek and Saniuk, 2015). Rapid supply chain reconfiguration through IoT and Cyber Physical Systems (CPS), Virtualization (Verdouw et al. 2016; Murray et al. 2010)

Intelligent Decision Making: predictive scheduling, fuzzy logic systems (Sobaszek et al. 2017; Gola and Klosowski, 2017). Smart Systems thinking (Caputo, 2019); Organisational and deep-learning systems (Edwards, 2009); Collaborative learning environments for SMS (Bahle et al. 2016); Trans-sectoral technology transfer mechanisms (Karagouni, 2018). Integration of Knowledge Management (KM) into systems analysis within product design systems (ElMaraghy, 2009); Sobaszek et al. 2017); Innovation Readiness Models (Javahernia and Sunmola, 2017). Innovation, competency management, collaborative work practices, social dimensions, human rights, ergonomics, and safety (Mrugalska and Arezes, 2013)Energy-neutral and Energy-efficient technologies. Systems through Internet of Things (IoT) (Shrouf et al. 2014); (Katchasuwanmanee et al. 2017), Digital Twins Damjanovic-Behrendt and Behrendt (2019), Ding et al. 2019. Waste reduction and energy monitoring through supply chains (Herrmann, 2015). Customer/supply chain connectivity: Jain and Benyoucef, 2008; Christopher and Towill, 2000). Digitally supported team collaboration systems (Rauch et al. 2016). Company/Knowledge base collaboration, e-Word of Mouth (e-WOM), and Digital marketing: Jeong and Koo (2015); Jalilvand and Samiei, (2016); (Yu et al. (2017); (Abubakar, 2016); Efficiencies through job resetting, redesign and collaboration (Habraken and Bondarouk, 2017); Smart Humand Resources 4.0 (HR4.0) (Sivathanu and Pillai, 2018). Ghobakhloo and Fathi (2019), SMS maturity models for SMEs (Mittal et al. 2018); Adoption Frameworks (Mittal et al. 2020); Social Capital and Leadership in SMEs (Agostini and Nosella. 2019); SME readiness for SMS implementation (Lin et al. 2020). Technology management, control, and monitoring (Zawadzki and Zywicki, 2016); (Gola and Klosowski, 2017), (Moeuf et al. 2018), (Zilch and Schalla 2015); Fit Manufacture (Rahman and Rahman 2019), (Pham et al. 2011); Smart Inventory modelling (Zheng and $\mathrm{Wu}$, 2017). I.E 4.0/Lean Integration (Sony, 2018). Management 4.0 (Oswald and Muller, 2018)

Digital supply chains, data analytics, cyber physical systems (Tu, 2016; Ardito et al. 2018), Big Data/Smart Systems connectivity (Caputo, 2019), Big data analytics on environmental impacts (Jeble, 2016; Hopkins and Hawking, 2015). Blockchain and Cyber Physical Systems (Barenji et al. 2020); Cloud Manufacturing: He and Xu (2015); Digital Twins Damjanovic-Behrendt and Behrendt (2019), Ding et al. 2019. Collaborative manufacturing environments for SMS integration (Thomas et al., 2019). Digital Readiness assessments for Industry 4.0 (I.E 4.0) in SMEs (Priola et al. (2019); collaborative investment in SME for I.E 4.0 technologies (Bosman et al. 2019); Cyber Physical Systems in SMEs, (Ferriera et al. 2020). Manufacturing Execution Systems (Menezes et al. 2018) 


\subsection{Smart Manufacturing Systems, an SME Perspective}

The development of SMS has brought a new era of information use through which businesses are able to collect, analyse and measure their productivity and develop specific solutions in order to continually improve their manufacturing performance. Whilst the benefits and uses of cyber-connected systems offered by SMS are many, evidence suggests that SMEs are still not convinced of their applicability into their organisations and frequently do not understand SMS and confuse the use of advanced manufacturing technology as being the same as using Smart Manufacturing Systems, often failing to identify that it is the cyber/internet connectivity that is the essential issue in developing and implementing SMS [5,11]. Companies must distribute knowledge faster before competitors acquire the same knowledge and therefore, smaller SMEs may need to focus on the Internet of Things (IoT) element of SMS through strengthening their internet operations as opposed to driving their manufacturing technology expertise [11].

A recent study into the adoption of Industry 4.0 technologies in SMEs [12] identifies that the attitudes of European manufacturing SMEs towards the implementation of such technologies and systems is highly variable ranging from significant levels of adoption of technologies (in Denmark for instance) through to relatively low levels of implementation amongst UK manufacturing SMEs. Impediments to the adoption of such technologies in UK SMEs include risks around cyber security, a lack of common standards allowing different technologies to connect, access to funding to support investment and the lack of suitable training and competency development amongst their workforce to adopt the technologies [5]. This report also includes that whilst SMEs stand to gain significant benefits from the adoption of Industry 4.0, most German SMEs do not have a comprehensive strategy towards the systematic development and adoption of such technologies into their respective organisations. Without such a vision and plan, SMEs often neglect the importance of keeping SMS on their agenda. A study by [13] also identified that whilst SMS technologies and systems can and are being adopted by SMEs, these technologies are not well mastered by SMEs, thus leading to incorrect adoption or, an under-exploitation of implementation. A lack of expertise in SMEs slows the implementation of certain technological groups. The study identifies that the exploitation of different SMS technologies is often approached individually and in a targeted manner which leads to the conclusion that the concept of SMS implementation is not approached from a collaborative perspective [14].

In summary, existing research suggests that SMEs are hampered in their quest to implement SMS due to a lack of strategic intent, and a lack of knowledge around SMS capabilities and implementation. A lack of collaboration between knowledge providers and collaborative industry partners has contributed to these failings. A literature review is now undertaken to review the area of Smart Systems.

\subsection{A Review and Analysis of Smart Manufacturing Systems}

This literature review identifies the empirical research work undertaken in Smart Manufacturing System development in manufacturing SMEs. A systematic review method is employed [15]. Eight search queries were applied to each of four key databases. The search queries were: "Smart Manufacturing Systems in SMEs"; "Industry/Industrie 4.0 in SMEs"; "Digital manufacturing technologies in SMEs"; "Internet of things in SMEs"; "Cyber physical systems in SMEs"; "Smart factories in SMEs"; "Collaborative systems" AND "Smart Manufacturing Systems": "Management systems" AND "Smart Manufacturing Systems". The databases selected followed the approach of [16] and included: Elsevier (http:/ / www.sciencedirect.com/); Emerald (http:/ / www.emeraldinsight.com/); Springer (http://link.springer.com/); Taylor and Francis (http://tandfonline.com/). This initial search yielded 4156 publications. No date or article type restrictions were applied, although patents, case law, citations and non-English articles were subsequently excluded as were duplicate papers and papers which did not specify the size of the companies in their research. Search string matches were sought in publication titles, author-supplied keywords or abstracts. Furthermore, the authors focused on articles that that were empirical in nature. 
Five additional publications were found through a general internet search. This work yielded a total of 65 publications. Tables 1 and 2 outline the results of the literature review and identifies the specific SME related SMS technologies and systems. Further information relating to these tables is given later in the paper.

The review highlighted a number of key manufacturing technologies applied to SMEs. However, the reviewed publications show that not all the groups of technology relating to Smart Manufacturing Systems are being implemented in SMEs. The technologies implemented in SMEs tend to focus on three key areas, namely: digital technologies (Blockchain, digital twins, cyber physical systems etc.), time compression technologies (3D printing, virtual prototyping, rapid tooling) and intelligent product design and decision-making systems. Furthermore, the literature also identifies a number of management themes which specifically focus on knowledge management, collaborative networks, technology readiness and maturity modelling. A number of articles also focus on the application of SMS and reflect upon the impact that such technologies have on the manufacturing performance within SMEs. From the analysis of the literature the authors were able to categorise the technologies and management systems into nine SMS thematic areas split into three key thematic areas. Further discussion of these thematic areas follows.

\subsubsection{Thematic Area 1-Applications and Performance}

Applications of SMS technologies and systems focussing upon reducing time to market for products and services thus making SMEs more responsive to market demands and needs. 3D printing and virtual prototyping allow SMEs to develop agility strategies through quicker product development etc. In addition, the research highlights the technologies and collaborative innovation systems surrounding intelligent product design, using data analytics to identify customer needs and the use of advanced product development software to rapidly develop new and innovative products for wider customer bases. Associated with the manufacturing technologies is a body of knowledge associated with rapid supply chain and value chain reconfiguration through IoT and cyber physical systems (CPS) and virtualization technologies. Effective supply chain mapping, collaborative working environments and innovative working environments to enable rapid reconfiguration and agility in value chains are also identified within an SME context.

\subsubsection{Thematic Area 2-Management Systems and Collaborative Networks}

SMS technologies and systems that link humans to computer systems specifically around intelligent decision making, predictive scheduling, fuzzy logic systems as well as organisational and deep-learning systems and collaborative learning environments. Additionally, research was identified around the use of SMS technologies and systems towards creating energy-neutral environments and waste-free manufacturing environments driven by advanced manufacturing technologies and monitoring systems. Furthermore, collaborative networks and management systems have developed through digitally connected collaborative networks integrating geographically dispersed teams to collaborate on projects as well as collaborative systems around technology adoption and SMS implementation in SMEs.

\subsubsection{Thematic Area 3-Digital Technologies}

Specific digital technologies that connect supply chains through cyber physical systems. Cloud manufacturing including digital readiness frameworks for the implementation of technologies. Virtualization of supply chains using SS technologies [5] enabling companies to optimise supply chain operations and characterise the dynamic nature of operations [7]. Virtualisation technologies that show the ability to apply innovations and improvements in supply chains, and to subsequently plan for and assess these innovations without affecting the manufacturing system. 
Table 2. Literature Analysis and Identification of SMS Clusters.

\begin{tabular}{|c|c|c|c|c|c|c|c|c|c|}
\hline \multirow{2}{*}{ Authors } & $\begin{array}{c}\text { Time } \\
\text { Compression }\end{array}$ & $\begin{array}{c}\text { Product } \\
\text { Innovation }\end{array}$ & $\begin{array}{l}\text { Reconfigurable } \\
\text { Value Chains }\end{array}$ & Human Factors & $\begin{array}{l}\text { Knowledge } \\
\text { Management }\end{array}$ & $\begin{array}{l}\text { Environmental } \\
\text { Systems }\end{array}$ & $\begin{array}{l}\text { Collaborative } \\
\text { Networks }\end{array}$ & $\begin{array}{c}\text { Management } \\
\text { Systems }\end{array}$ & Digital Systems \\
\hline & \multicolumn{3}{|c|}{ Manufacturing Performance } & \multicolumn{5}{|c|}{ Management Systems } & Technologies \\
\hline [1] & & & & & & & $\bullet$ & • & \\
\hline [2] & & & & & & & & $\bullet$ & \\
\hline [3] & & & & & & $\bullet$ & & $\bullet$ & \\
\hline [4] & & & & & & & $\bullet$ & $\bullet$ & \\
\hline [6] & & & & & & & $\bullet$ & & \\
\hline [7] & & & & & & & $\bullet$ & $\bullet$ & \\
\hline [8] & & & & & & & & $\bullet$ & \\
\hline [9] & & & & & & & & $\bullet$ & \\
\hline [10] & & & & & & & & $\bullet$ & \\
\hline [11] & & & & & & & & $\bullet$ & $\bullet$ \\
\hline$[13]$ & & & & & & & & $\bullet$ & - \\
\hline$[14]$ & & & & & & & & $\bullet$ & \\
\hline [15] & & & & & $\bullet$ & & & $\bullet$ & \\
\hline [16] & $\bullet$ & $\bullet$ & & & & & & & $\bullet$ \\
\hline [17] & $\bullet$ & $\bullet$ & $\bullet$ & & & & & & $\bullet$ \\
\hline [18] & $\bullet$ & & & & & & & & $\bullet$ \\
\hline [19] & $\bullet$ & & & & & & & & $\bullet$ \\
\hline [20] & $\bullet$ & $\bullet$ & & & & $\bullet$ & & & $\bullet$ \\
\hline [21] & & $\bullet$ & & & & $\bullet$ & & & $\bullet$ \\
\hline [22] & $\bullet$ & & & & & & $\bullet$ & & $\bullet$ \\
\hline
\end{tabular}


Table 2. Cont

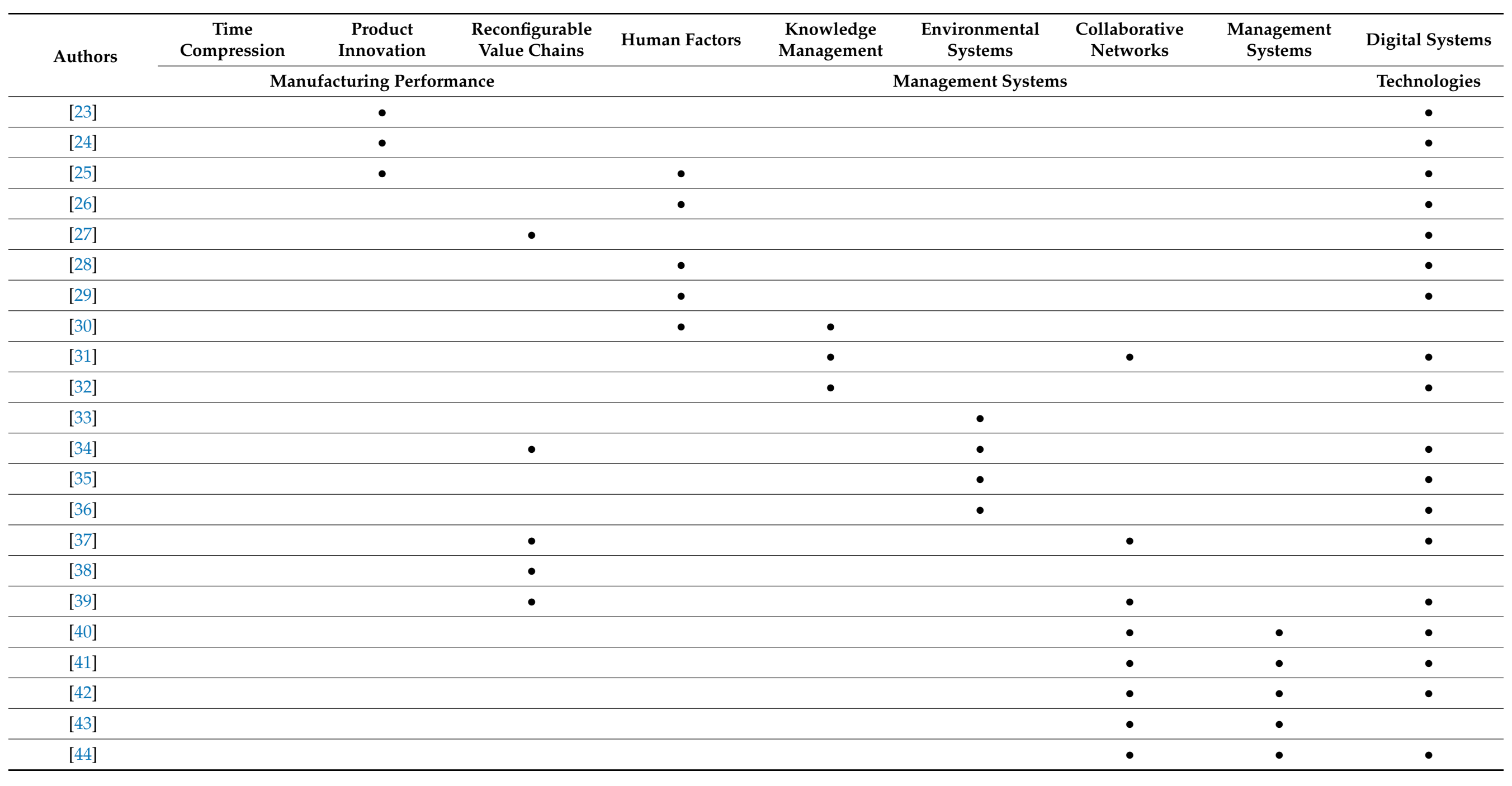


Table 2. Cont

\begin{tabular}{|c|c|c|c|c|c|c|c|c|c|}
\hline \multirow{2}{*}{ Authors } & $\begin{array}{c}\text { Time } \\
\text { Compression }\end{array}$ & $\begin{array}{c}\text { Product } \\
\text { Innovation }\end{array}$ & $\begin{array}{l}\text { Reconfigurable } \\
\text { Value Chains }\end{array}$ & Human Factors & $\begin{array}{l}\text { Knowledge } \\
\text { Management }\end{array}$ & $\begin{array}{c}\text { Environmental } \\
\text { Systems }\end{array}$ & $\begin{array}{l}\text { Collaborative } \\
\text { Networks }\end{array}$ & $\begin{array}{l}\text { Management } \\
\text { Systems }\end{array}$ & Digital Systems \\
\hline & \multicolumn{3}{|c|}{ Manufacturing Performance } & \multicolumn{5}{|c|}{ Management Systems } & Technologies \\
\hline [45] & & & & & & & $\bullet$ & & $\bullet$ \\
\hline [46] & & & & & & & $\bullet$ & & $\bullet$ \\
\hline [47] & & & & & & & & & - \\
\hline [48] & & & & & & & & $\bullet$ & $\bullet$ \\
\hline [50] & & & & & & & - & $\bullet$ & \\
\hline [51] & & & & & & & & $\bullet$ & $\bullet$ \\
\hline [52] & & & & & & & & $\bullet$ & $\bullet$ \\
\hline [53] & & & & & & & & $\bullet$ & • \\
\hline [54] & & & & & & & & • & • \\
\hline [55] & & & & & & & & $\bullet$ & $\bullet$ \\
\hline [57] & & & & $\bullet$ & $\bullet$ & & $\bullet$ & $\bullet$ & . \\
\hline [58] & & & • & & & & & & $\bullet$ \\
\hline [59] & & & $\bullet$ & & & & & & • \\
\hline [60] & & & & & & $\bullet$ & & & $\bullet$ \\
\hline [61] & & & & & & - & & & • \\
\hline [62] & & & $\bullet$ & & & $\bullet$ & & & $\bullet$ \\
\hline [63] & $\bullet$ & $\bullet$ & & & & $\bullet$ & & & $\bullet$ \\
\hline [64] & & & & & & & & • & $\bullet$ \\
\hline [65] & & & & & & & & - & • \\
\hline [66] & • & $\bullet$ & & & & & & & • \\
\hline
\end{tabular}


Table 2. Cont

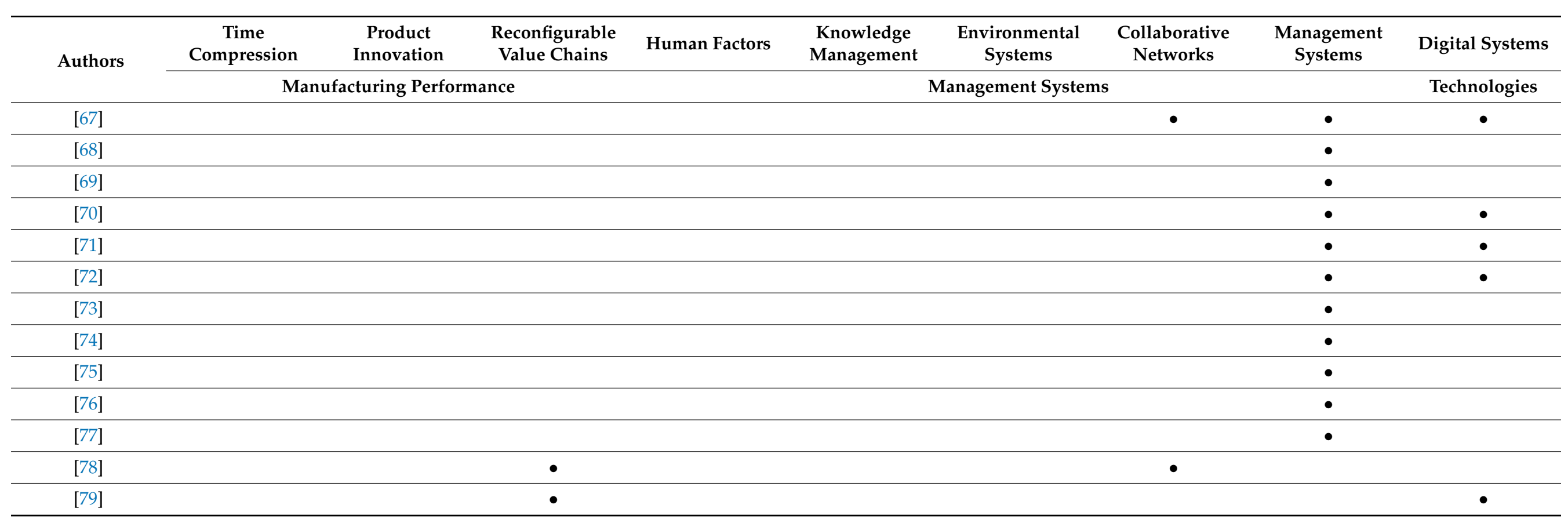


Table 2 provides a further analysis of the empirically based literature and shows the identification and development of nine key SMS cluster areas that emerged from the review. The cluster areas were identified by the authors through a detailed examination of each of the 65 papers. In each case, the technologies and systems discussed in the publications were identified and used to develop the table. Publications showing the interconnectivity between the technologies, the management systems and the associated application and impact on the manufacturing performance were of particular interest. The table provides a useful analysis of the coverage of the research work around SMEs and further highlights the interconnected nature of the research with an increasing focus on the need for effective management systems to support the standard SMS technologies.

\section{Research Method and Survey Design}

A triangulated research approach was adopted for this study. Part 1 consisted of a literature review which identified the key research around SMS technologies and systems in SMEs (previously described). Part 2 analysed the information obtained from the literature review to create a questionnaire. Part 3 involved the use of the questionnaire to survey 36 SMEs from which an SME profile was created with interviews being conducted to further contextualize the findings of the study. Figure 1 shows research method and survey design process adopted in this study.

Research Study Stage

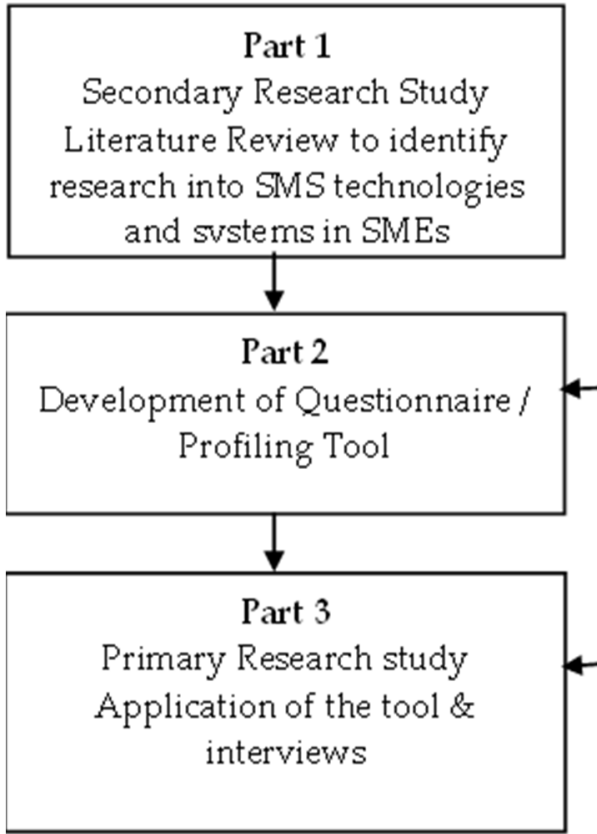

Data Collection Methods Employed

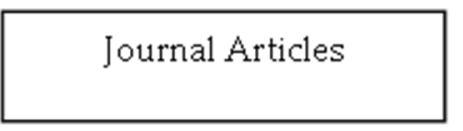

\section{Data Validation \\ Methods Employed}

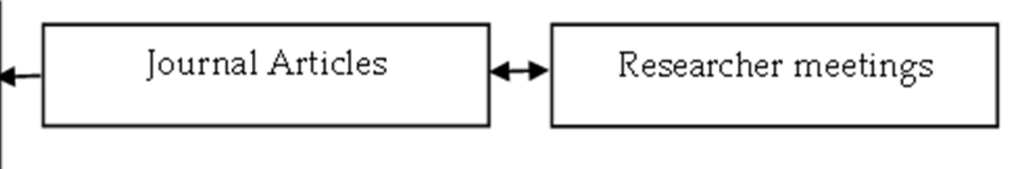

Figure 1. Research Method and Survey Design.

\subsection{The Survey and Observation Process}

Appendix A shows the questionnaire that was developed in order to undertake the primary research phase. The questions were initially developed from the nine key SMS clusters identified from Phase 1 of the study and shown in Table 2. Initial testing of the questionnaire with 2 test bed companies, showed that the tool was insufficiently sensitive for identifying the specific technologies and systems employed by the SMEs. During the initial testing phase, issues emerged around trying to obtain consensus and understanding amongst the SMEs as to what specific technologies and systems would fit into the key cluster areas. This made subsequent analysis difficult. Therefore, the authors undertook a third level of literature analysis to further refine the tool where the nine cluster areas were subsequently broken down to identify a further two SMS dimensions for each cluster thus 
creating 18 SMS dimensions overall. Further testing of the 18 SMS dimensions using the 5-point Likert scale provided improved clarification and understanding and was therefore deemed suitable for application to the wider-scale project.

The questionnaire required each Managing Director (MD) to rate or score their company's current level of expertise in the eighteen dimensions using a Likert scale (1-5) where a Likert value of " 1 " indicated the company had little or no expertise in the SMS dimension whereas a Likert value of " 5 " indicated that the company had substantial expertise of implementing and utilizing the SMS dimension. Alongside the responses received from the MDs, the questionnaire also incorporated an "observation" section that allowed the researcher to observe the technology dimensions being applied in company. This was achieved through a detailed audit of company operations where the researcher was able to assess and score each dimension on the same 1-5-point Likert scale. Once the survey and audit of operations was complete, the researcher and MD discussed the MD/researcher derived scores and came to a consensus on the appropriate score where any differences in score existed. This enabled further moderation of the score for each dimension to occur.

One hundred and three requests were issued electronically to a range of manufacturing SMEs in Wales and the West of England. These were selected at random from the University database of manufacturing SMEs. Thirty-six SMEs responded and agreed to undertake the survey. From this response, the Standard Industry Classification (SIC) codes of the companies were then analysed and three company categories were identified. Fourteen SMEs were classified as Mechanical/Manufacturing engineering companies, sixteen SMEs were classified as Food production companies with a further six SMEs being classified as electrical/electronic manufacturing companies. Each company agreeing to take part was contacted by the authors and an initial meeting was arranged to discuss the questionnaire/profiling tool and to explain the 18 SMS dimensions. In all cases, the nominated Director of each company participated in the survey.

\subsection{Survey Data Collection, Analysis and Validation}

The survey was conducted between the researcher and the Directors of each company. Scores were assigned to each of the 18 SMS dimensions by the Director. A series of moderation events were undertaken in order to validate the survey responses. This included one in every four companies being visited by two researchers and further moderation meetings held amongst the researcher team to ensure scores were being awarded consistently. Furthermore, the researchers validated the claims made by the MDs by undertaking an audit of company operations through observing practices and mapping these observations to the survey responses (as previously described). Column 3 of Table 3 shows the current level of expertise. The second stage of scoring required the MD to prioritise each SMS dimension based on a two-year planning horizon (i.e., where they thought their company needed to be to meet the demands of their industry) column 4 shows the 2 -year priority score. The resulting profiling developed from the profiling tool is shown in Section 4 of this paper. The work enabled the team to determine the current state of operational excellence and also the strategic intent of each company in meeting the SS requirements. This provided the authors with an indicator of the strategic intent of the manufacturing SMEs [3]. 
Table 3. The SMS Profile.

\begin{tabular}{|c|c|c|c|c|c|c|c|c|c|}
\hline \multirow{2}{*}{$\begin{array}{l}\text { SMS } \\
\text { Clusters }\end{array}$} & \multirow{2}{*}{ SMS Dimensions } & \multirow{2}{*}{$\begin{array}{l}\text { Average Current } \\
\text { Level of Expertise }\end{array}$} & \multirow{2}{*}{$\begin{array}{l}\text { Average } 2 \text { Year } \\
\text { Priority Score }\end{array}$} & \multirow{2}{*}{ Gap } & \multicolumn{5}{|c|}{ Level of Current Expertise } \\
\hline & & & & & 1 & 2 & 3 & 4 & 5 \\
\hline \multirow{2}{*}{$\begin{array}{c}\text { Time to } \\
\text { Market } \\
\text { compression }\end{array}$} & $\begin{array}{l}\text { D1 Customer Integration with } \\
\text { product development process }\end{array}$ & 4.3 & 4.8 & 0.5 & 0 & 1 & 2 & 15 & 14 \\
\hline & $\begin{array}{l}\text { D2 Application of time } \\
\text { compression technologies }\end{array}$ & 3.8 & 4.6 & 0.8 & 0 & 1 & 11 & 12 & 8 \\
\hline \multirow{2}{*}{$\begin{array}{l}\text { Product } \\
\text { Innovation }\end{array}$} & $\begin{array}{c}\text { D3 Robust New Product } \\
\text { Development/Introduction } \\
(\mathrm{NPD} / \mathrm{I})\end{array}$ & 4.4 & 4.6 & 0.2 & 0 & 0 & 1 & 16 & 15 \\
\hline & $\begin{array}{l}\text { D4 Intelligent and Customised } \\
\text { products }\end{array}$ & 3.9 & 4.5 & 0.6 & 0 & 2 & 8 & 12 & 10 \\
\hline \multirow{2}{*}{$\begin{array}{l}\text { Human } \\
\text { Factors }\end{array}$} & $\begin{array}{l}\text { D5 R and D Systems/Co- } \\
\text { Innovation/creativity }\end{array}$ & 3.4 & 4.2 & 0.8 & 3 & 4 & 8 & 9 & 8 \\
\hline & D6 Competency management & 3.1 & 4.7 & 1.6 & 5 & 6 & 7 & 7 & 7 \\
\hline \multirow{2}{*}{$\begin{array}{l}\text { Knowledge } \\
\text { Management }\end{array}$} & $\begin{array}{l}\text { D7 Organisational Learning } \\
\text { systems }\end{array}$ & 1.9 & 4.7 & 2.8 & 14 & 10 & 5 & 3 & 0 \\
\hline & $\begin{array}{c}\text { D8 Intelligent } \\
\text { decision-making systems }\end{array}$ & 2.7 & 4.7 & 0.6 & 0 & 0 & 8 & 12 & 12 \\
\hline \multirow{2}{*}{$\begin{array}{l}\text { Environmental - } \\
\text { Systems }\end{array}$} & D9 Waste Reduction Systems & 4.3 & 4.8 & 0.5 & 0 & 0 & 3 & 17 & 12 \\
\hline & $\begin{array}{l}\text { D10 Energy-neutral } \\
\text { production systems }\end{array}$ & 3.5 & 5 & 1.5 & 3 & 2 & 8 & 11 & 8 \\
\hline \multirow{2}{*}{$\begin{array}{l}\text { Reconfigurable } \\
\text { Value Chains }\end{array}$} & $\begin{array}{l}\text { D11 Information-Sharing } \\
\text { Systems }\end{array}$ & 2.5 & 4.3 & 1.8 & 8 & 9 & 7 & 5 & 3 \\
\hline & $\begin{array}{l}\text { D12 Rapid Supply Chain } \\
\text { Reconfiguration }\end{array}$ & 3.7 & 4.2 & 0.5 & 0 & 2 & 11 & 11 & 8 \\
\hline \multirow{2}{*}{$\begin{array}{l}\text { Collaborative } \\
\text { Networks }\end{array}$} & $\begin{array}{l}\text { D13 Customer and Supply } \\
\text { Chain Collaboration }\end{array}$ & 2.6 & 4.0 & 0.7 & 2 & 6 & 8 & 9 & 7 \\
\hline & $\begin{array}{l}\text { D14 Company/University } \\
\text { Collaboration }\end{array}$ & 2. & 4.7 & 2.6 & 7 & 14 & 8 & 2 & 1 \\
\hline \multirow{2}{*}{$\begin{array}{l}\text { Management } \\
\text { Systems }\end{array}$} & D15 Manufacturing Fitness & 4.0 & 4.4 & 0.4 & 0 & 0 & 9 & 13 & 10 \\
\hline & $\begin{array}{c}\text { D16 Technology Management } \\
\text { Systems }\end{array}$ & 4.1 & 4.5 & 0.4 & 0 & 0 & 5 & 16 & 11 \\
\hline \multirow{2}{*}{$\begin{array}{l}\text { Digital } \\
\text { Systems }\end{array}$} & $\begin{array}{l}\text { D17 Digitally Connected } \\
\text { Supply Chains }\end{array}$ & 1.6 & 4.9 & 3.3 & 16 & 13 & 2 & 1 & 0 \\
\hline & $\begin{array}{l}\text { D18 Data analytics and } \\
\text { Production Analytics }\end{array}$ & 1.5 & 4.6 & 3.1 & 16 & 15 & 1 & 0 & 0 \\
\hline
\end{tabular}

\subsection{Semi-Structured Interviews}

Following the survey and observation work, the MD and researcher then entered into the interview stage. Appendix A shows the five questions asked during the semi-structured interview stage. These questions were developed from the thematic areas identified in Table 1 where the MDs were asked to discuss their overall strategies towards using SMS to improve: productivity and performance, their management systems, collaborative networking and the typical digital technologies that were seen as critical towards achieving and/or maintaining business sustainability in the future.

Information gained from the interviews with the MDs was collected by the researcher team and a series of focus group meetings were held amongst the research team to analyse the information. The analysis stage enabled the researcher team to discuss the information obtained from all 36 companies and allowed the team to map the qualitative information to the initial survey data and the additional observation information from the company visits. 
From this analysis, a number of key areas emerged, namely: current and future production challenges, current and future strategies, current and future technologies and systems. The information from this phase of work was analysed alongside the survey data and is represented in the Discussion section later in this paper. This phase of work provided further contextual information to support the survey work previously undertaken. More importantly, it allowed the research team to gain a greater understanding of the competitive pressures facing the surveyed companies and the strategic approaches that were being considered or adopted to meet the future manufacturing challenges.

\section{Survey Results-General Findings}

Table 3 presents an average score of the 36 manufacturing SMEs on their assessment of their current technological expertise, and also their two-year strategic priority score. All SMEs selected for the study had previously implemented advanced manufacturing technologies and systems and were aware of SMS technologies (although discussions were held with the MD of each company to ensure they all had the same baseline information relating to SMS). Table 3 also shows a frequency analysis indicating the number of respondent scores provided against each technology area. This enabled the researchers to understand the relative level of expertise each company had in relation to the technology areas. Table 4 shows the profile of the companies who took part in the study. Figure 2 shows the overall profile of all 36 SMEs examined in this study. Taking the top four criteria from this figure shows that the SMEs new product development and introduction capabilities, along with their customer integration, waste reduction, and technology management expertise, were considered to be strong and well-developed. The SMEs scored less well in five key areas, namely: knowledge base collaboration, information sharing, organizational learning, digital connectedness, and data analytics. Figure 2 also shows the average 2-year strategic priority scores offered by the sample group of companies. The 2-year priority profile is a measure of what the SMEs considered to be the key technologies and systems that need to be in place in order for the companies to remain competitive over the medium-term strategic planning horizon. The figure shows that the top five priority areas to focus on are: energy-neutral production systems, competency management, digitally connected supply chains, data analytics and university/company collaboration.

Table 4. The SMEs and sectors that responded to the survey.

\begin{tabular}{|c|c|c|c|c|c|}
\hline \multicolumn{2}{|c|}{ Manufacturing Sectors } & $\begin{array}{c}\text { Companies per } \\
\text { Sector }\end{array}$ & $\begin{array}{c}\text { Employees } \\
10-50\end{array}$ & $\begin{array}{c}\text { Employees } \\
\text { 50-150 }\end{array}$ & $\begin{array}{c}\text { Employees } \\
150-200\end{array}$ \\
\hline \multirow{3}{*}{ Mechanical } & Component manufacturing & 8 & 6 & & 2 \\
\hline & Machine Manufacturing & 3 & 2 & 1 & \\
\hline & Precision Engineering & 3 & 1 & 2 & \\
\hline \multirow{3}{*}{ Food } & Ready meal processing & 2 & & 2 & \\
\hline & Cheese and Dairy & 4 & 2 & 2 & \\
\hline & Bread, Bakery, and Snacks & 10 & 5 & 3 & 2 \\
\hline \multirow{4}{*}{$\begin{array}{l}\text { Electrical and } \\
\text { Electronics }\end{array}$} & Electrical Products & 2 & 2 & & \\
\hline & Electronic Systems & 3 & 1 & & 2 \\
\hline & Component Remanufacture & 1 & 1 & & \\
\hline & Totals & 36 & 20 & 10 & 6 \\
\hline
\end{tabular}




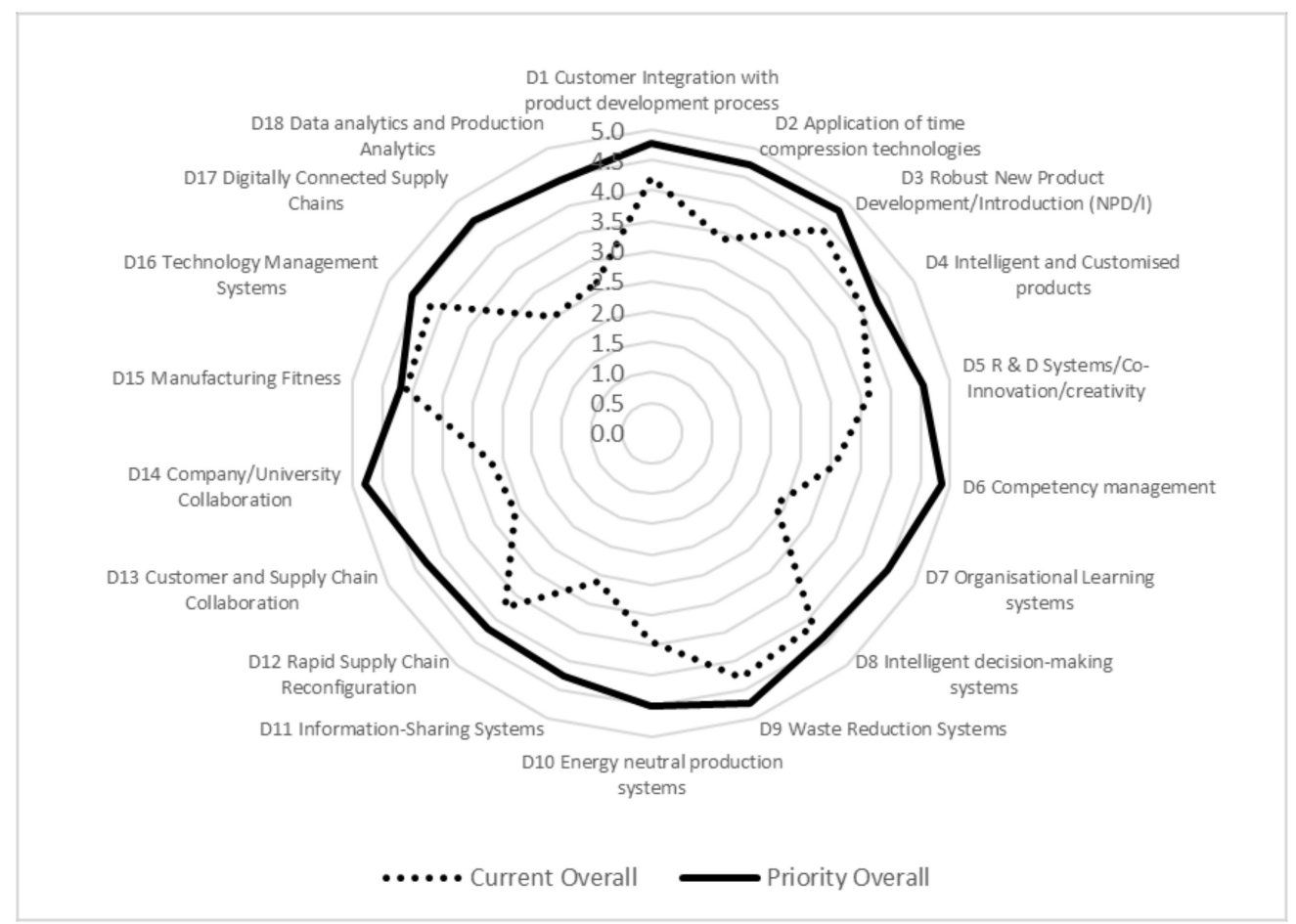

Figure 2. The analysis of current and future productivity profiles of all 36 manufacturing SMEs.

An analysis of the 2-year strategic priorities showed that in general, the companies saw the need to adopt and implement state-of-the-art technologies. In particular, the focus on reducing energy consumption and moving towards energy-neutral manufacturing systems is interesting, since companies felt that their waste reduction strategies were relatively well advanced but, company energy-reduction strategies needed further work and development. Of further interest was the need for "digitally connected supply chains". Although seen as a strategic priority, the companies did not see themselves having the current expertise (or knowledge of where to access the expertise) in order to move towards this technological area. This issue links strongly with the disparity seen between the current overall lack of development in the areas of competency management, knowledge management, and University/company collaboration. Most SMEs were driven towards the implementation of SMS as a result of political changes within the UK and this issue outweighed the potential barriers and internal issues, such as the costs of training and equipment, as they saw the threat of significant external change as being greater than the internal resistance that had previously been seen.

Further analysis of the data identified that the small SMEs (10-50 employees) in all three sectors provided higher than average scores in understanding the SMS technologies due in part to them having already implemented some small-scale SMS systems. In general, they understood better the need for the deployment of internet and SMS (small scale $3 \mathrm{D}$ printing, virtual prototyping connected through internet technologies). Although the technologies and systems that they identified in the discussions lacked the sophistication of the larger SMEs, the application of internet and cyber physical systems pertaining to their own production operations had at least been implemented to some extent. This finding can be attributed to the position of small SMEs in the supply chain where their position in the supply chain dictates the need to have advanced manufacturing and design capabilities since it was felt that many larger companies "sub-contracted" the innovations down through to the smaller companies. Through the development of closer collaboration within the supply chain, small SMEs benefited from greater opportunities to develop more customised products and services through the co-creativity of new products and innovative solutions to particular production issues. A particularly well-developed area amongst the small SMEs is the development of excellent supply chain collaboration practices between 
customer and supplier that are delivered through internet technologies (internet and social media platforms).

A particular strength of the medium-to-large SMEs was their ability to manage their technologies and to operate lean production systems as well as utilizing time compression technologies, such as automated systems. Therefore, two distinct patterns emerge from this study that emphasise the difference in attitudes between small SMEs and medium/larger SMEs. Smaller SMEs use less sophisticated technology but utilize their systems to better effect, linking their technologies to both the customer and the supplier in more of a traditional SMS approach, whereas medium-sized/Large SMEs employ more sophisticated technologies, but they lack the means to utilize the technologies to their maximum effect.

\subsection{Survey Results-Sectoral Analysis}

\subsubsection{Mechanical Manufacturing SMEs}

The mechanical manufacturing SMEs surveyed consisted of precision manufacturing companies and specialist jobbing shops. The technologies employed in these companies consisted of advanced Computer Numerically Controlled (CNC) and automated manufacturing machinery and design capability and connectivity to their manufacturing machinery and these technologies were embedded in all SMEs regardless of size of company. Figures 3 and 4 show the output from the auditing work undertaken with these companies. More specifically, the strategic priorities identified amongst micro-SMEs were: organizational learning systems, intelligent decision making, company/university collaboration, digitally connects supply chains and data analytics. MDs of these SMEs felt that the major issues in their organizations were people related and identified the need to build the level of knowledge in the company in order to fully exploit the capabilities of SMS. Developing further knowledge would enable the SMEs to fully exploit the use of data analytics as an example as well as develop more innovative concepts and systems through closer collaborations with Universities and other knowledge bases.

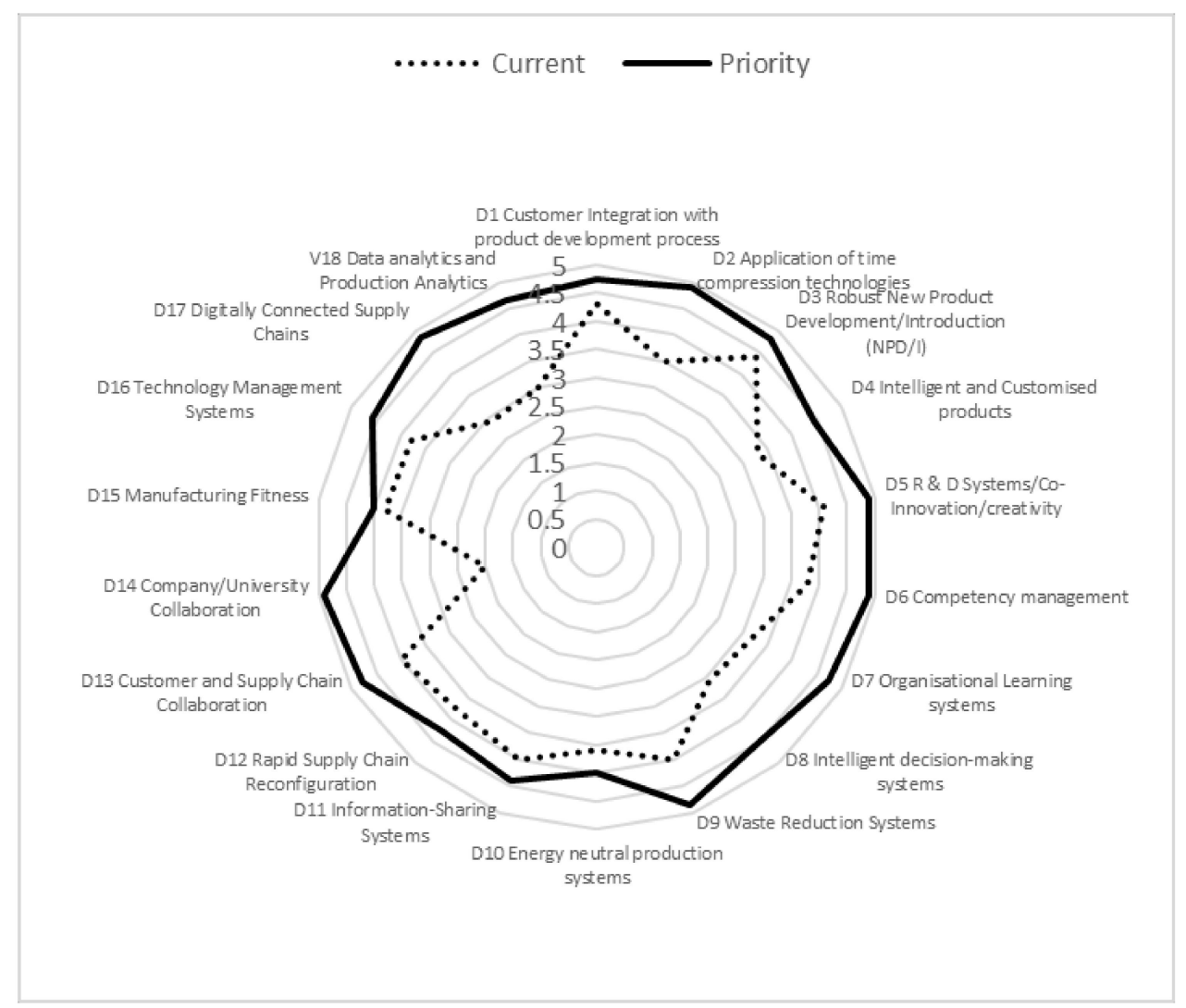

Figure 3. The analysis of current and future profiles of SMEs with 10-50 Employees-Mechanical. 


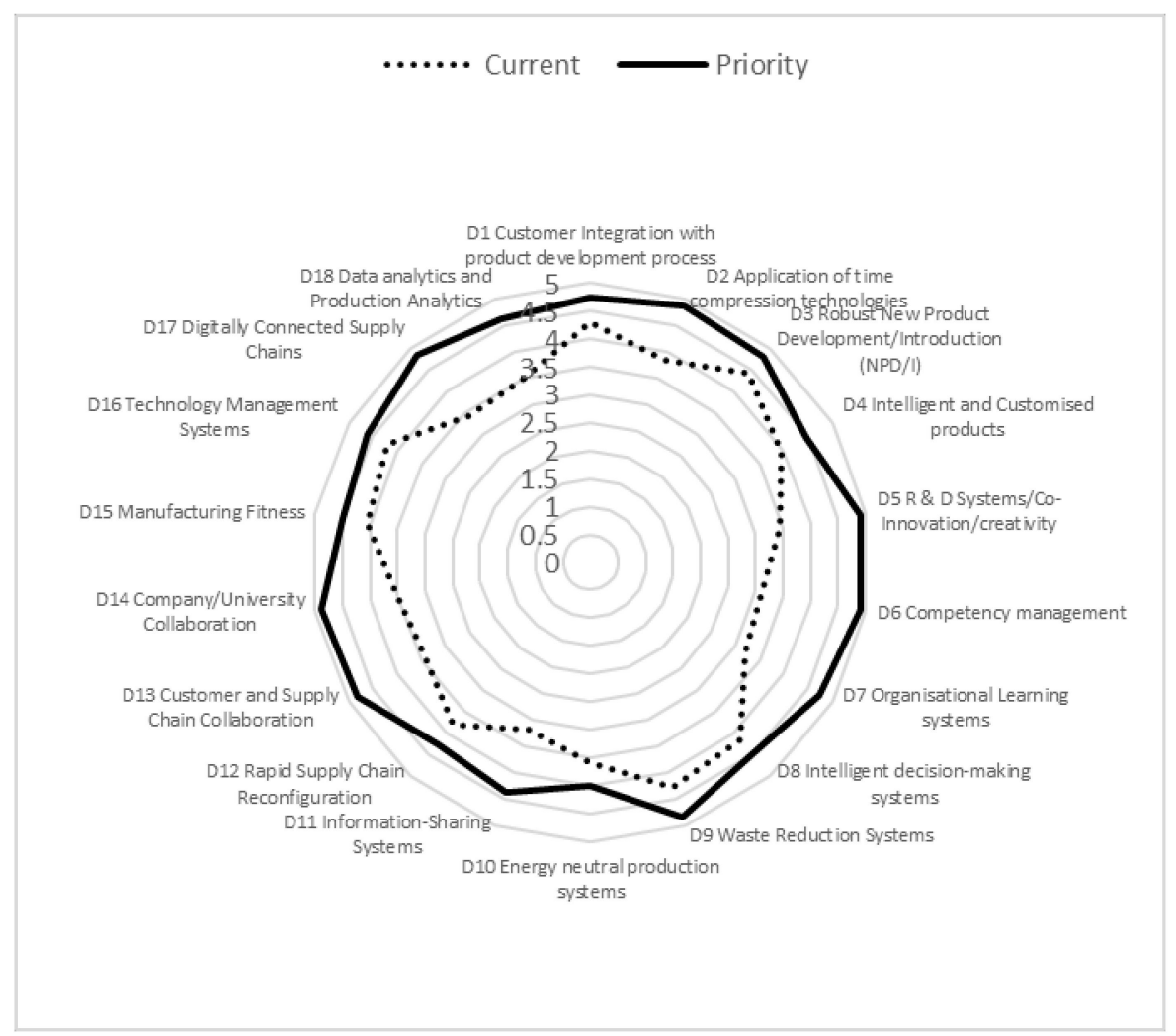

Figure 4. The analysis of current and future profiles of SMEs with 51-250 Employees-Mechanical.

For Medium/Large SMEs, the strategic priorities were $\mathrm{R}+\mathrm{D}$ systems and co-innovation, competency management, organizational learning systems. These priorities match many of those issues identified by the smaller SMEs. However, greater focus was on the need for greater levels of innovation and creativity required to develop company product range and levels of process innovation in order to remain competitive going forward.

\subsubsection{Food Production SMEs}

Food production SMEs were very different in structure and their technological capabilities were dependent upon the size of the organizations. Micro-SMEs generally tended to be artisan companies producing specialist food products using relatively standard technologies and systems. Figures 5 and 6 show the results of the auditing work undertaken with these SMEs. The strategic priorities identified amongst micro-SMEs were the need for more effective Organizational Learning systems and more focus on time compression technologies as a means of delivering new products to market quicker. However, the standard time compression technologies around 3D printing etc. were not considered appropriate. Rather, companies required greater connectivity to customers and a more rapid process of taking new products to market through effective NPD/I processes was key. The use of social media systems to drive e-WOM and developing collaborative networks to reduce logistics costs were seen as key. Other areas primarily around dimensions D13 to D18 were not considered appropriate or required by micro-SME food companies as they felt that they were unable to exploit such systems due to their size and relatively basic technological capabilities.

For medium/large SMEs, they tended to employ elementary robotic systems for pick and place activities as well as automated cells for rapid delivery of product through the production system. Their strategic priorities were co-innovation, competency management, organizational learning systems, information sharing, data analytics and digitally connected supply chains. Again, priorities around innovation, creativity and the associated knowledge and competency management were identified as a means to ensuring that the SMEs were able to fully exploit the technologies and systems available to them. 
In particular, their need to develop digitally connected supply chains was a key area of development in order to improve food chain traceability and tracking of products through the production system.

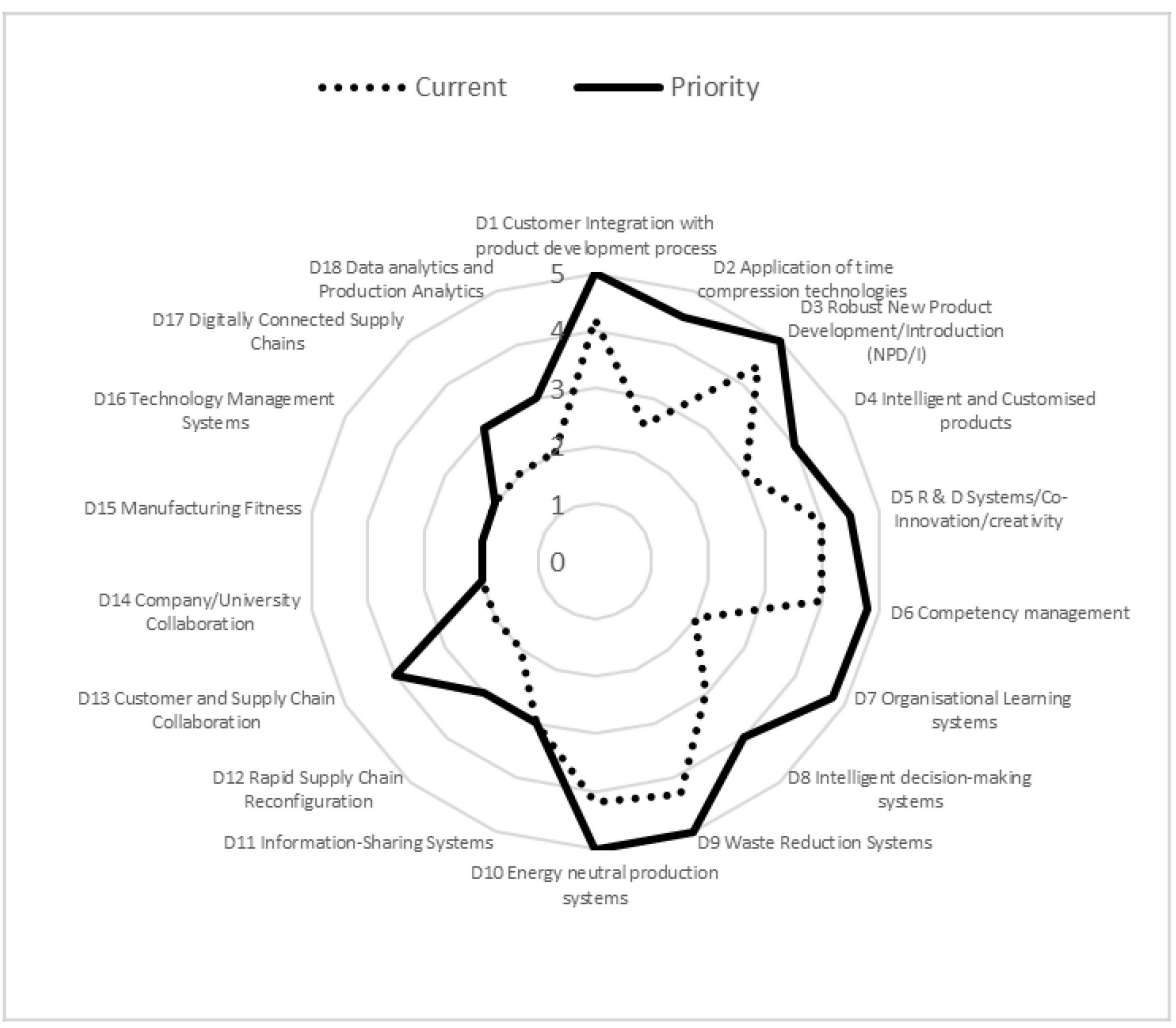

Figure 5. The analysis of current and future profiles of SMEs with 10-50 Employees-Food.

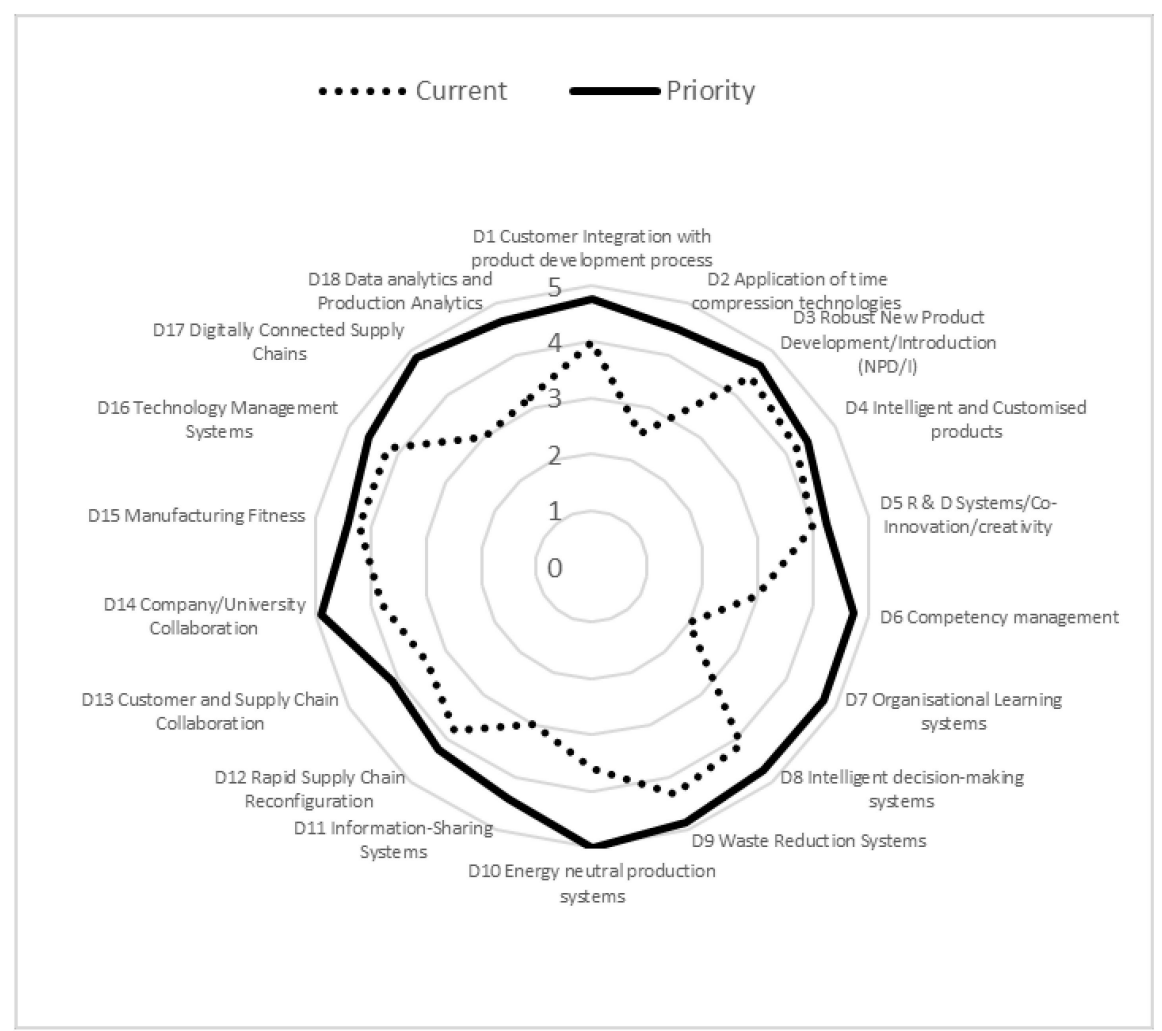

Figure 6. The analysis of current and future profiles of SMEs with 51-250 Employees-Food. 


\subsubsection{Electrical Product Manufacturing SMEs}

Electrical product manufacturing SMEs consisted of electrical component manufacturers employed mainly within automotive, white goods and aerospace supply chains and tier $2 / 3$ companies. The technologies employed were automated assembly systems including robotic pick and place systems as well as automated transfer systems as well as sophisticated product testing technologies. These technologies were seen in most companies regardless of size. Figures 7 and 8 show the results of the auditing work undertaken with these SMEs. The strategic priorities identified amongst micro-SMEs were: company/university collaboration, organizational learning systems, intelligent decisionmaking systems. Again, the strategic need was around human competency and knowledge management as well as an improved need to collaborate with knowledge bases. Intelligent decision-making systems focused upon rapid testing and decision-making systems around product testing and verification.

For medium/large SMEs, the strategic priorities were very similar to the microSMEs in that $\mathrm{R}+\mathrm{D}$ systems and co-innovation, organizational learning systems, energy management, supply chain reconfiguration and supply chain collaboration were seen as key priority areas for development. The supply chain interconnectivity and reconfiguration were seen as additional issues for larger SMEs operating within this sector.

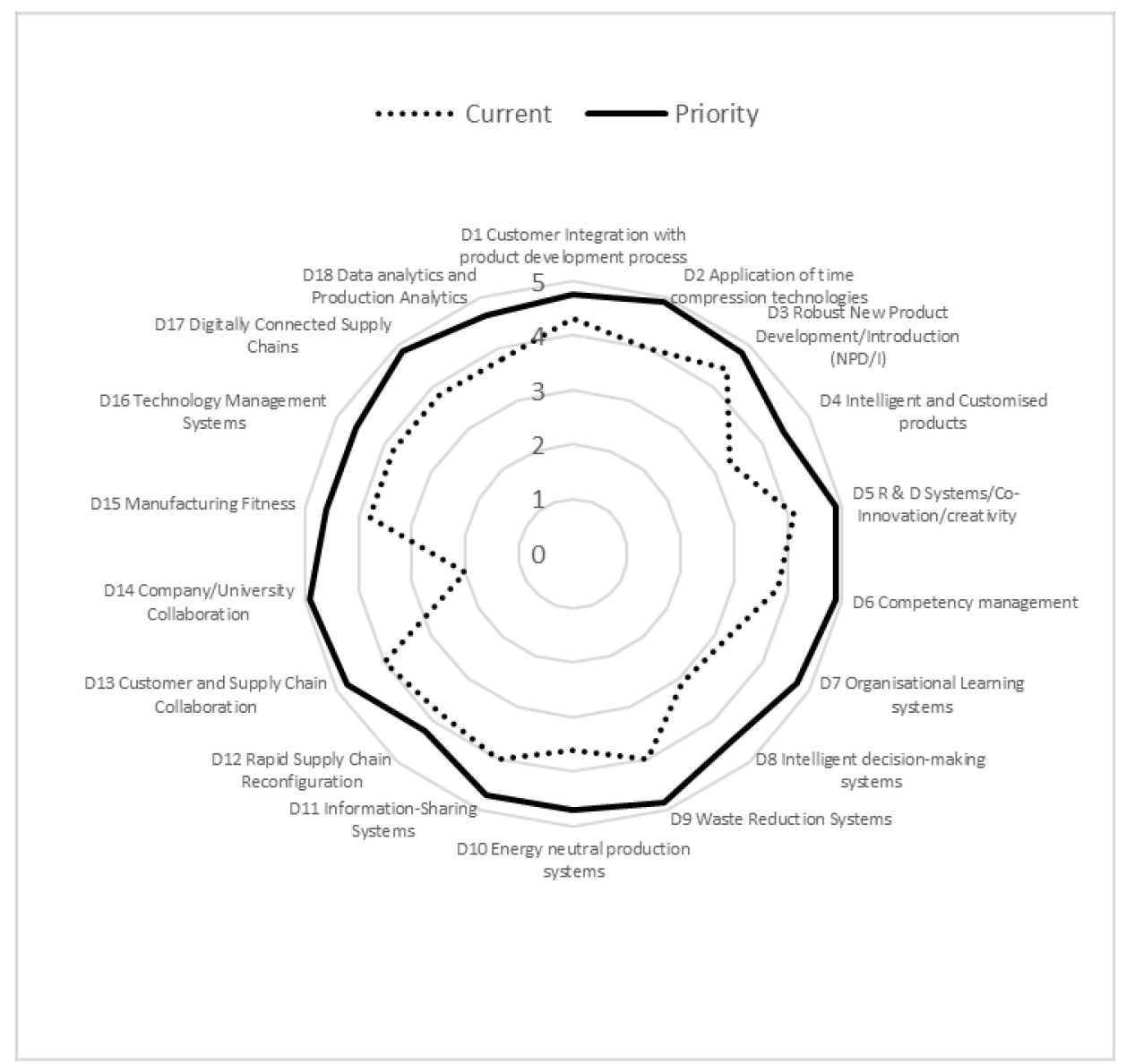

Figure 7. The analysis of current and future profiles of SMEs with 10-50 Employees-Electrical. 


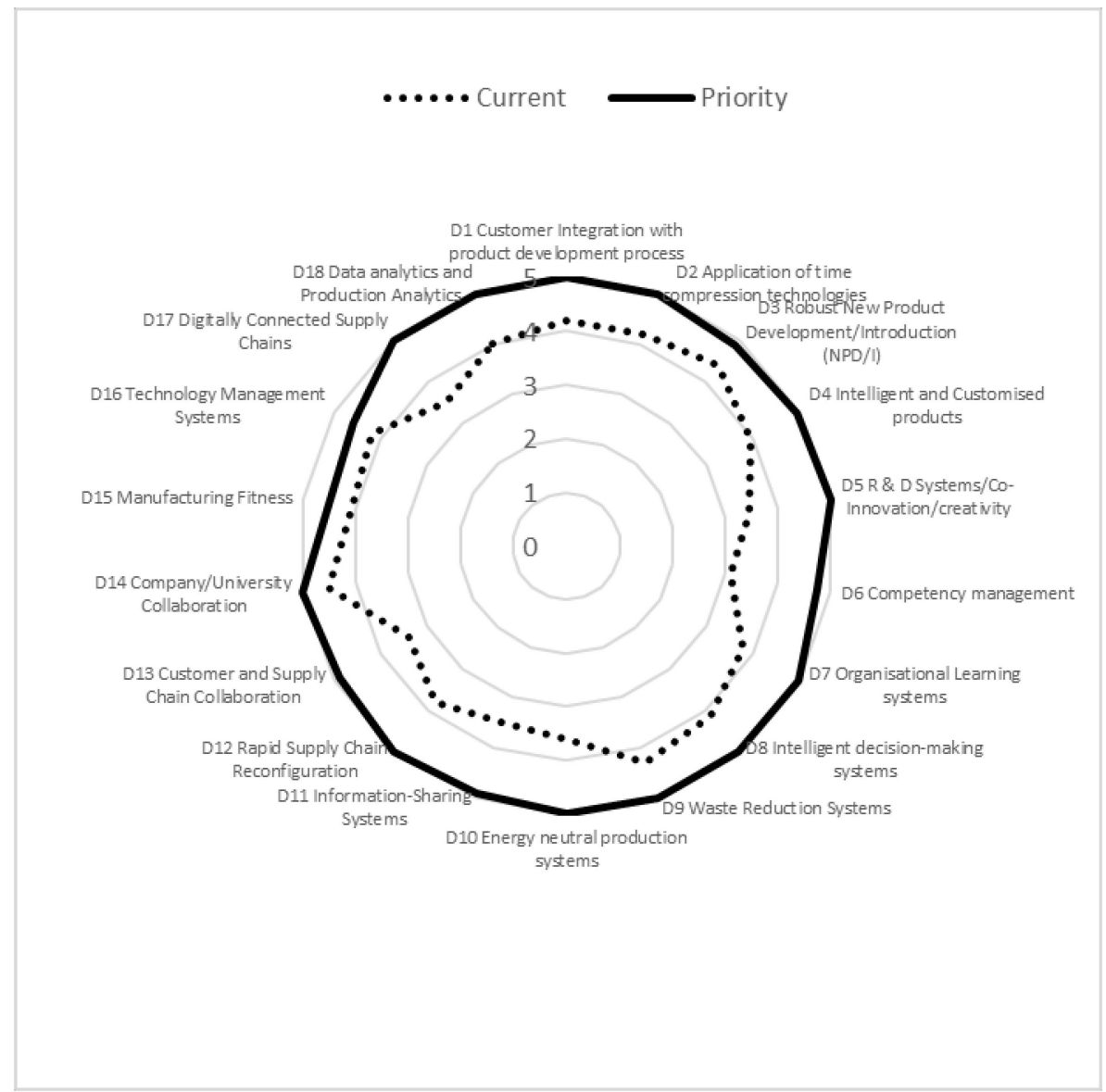

Figure 8. The analysis of current and future profiles of SMEs with 51-250 Employees-Electrical.

\subsubsection{Interview Results and Discussion}

The major strategic objective of all company owners surveyed and interviewed was ensuring their companies remained economically sustainable. In most cases, companies focused upon increasing the level of product and process innovation in an attempt to attract new customers but also to retain their existing client base. Utilization and implementation of new design and prototyping technologies were central to the MDs drive to develop new products or enhance the innovation around their manufacturing processes. In the case of the larger manufacturing companies, most felt that their ability to innovate especially around new product innovation was restricted due to the nature of their business and the fact that they were mainly structured as "manufacturing only" plants and therefore had little or no responsibility for product development. In these companies, controlling the cost of production and systematically reducing waste from their business processes through the application of lean management systems was the most prevalent and the primary driver.

Furthermore, medium/large SMEs did not fully exploit the data that were being produced on the back of their technologies. Data relating to machine outputs and performance were not used to develop new production and maintenance routines, and large data sets pertaining to customer current and future needs analysis were not exploited sufficiently to allow for more collaborative environments to exist between supply chain partners and customers. The smaller SMEs saw a definite need to use SMS and the associated IoT technologies around social media (in particular with micro food companies) to help predict customer needs and rapidly identify the customer satisfaction levels and also, to assist in identifying where competitors were investing in relation to new product development specifically in customized products and services [69].

In an attempt to remain sustainable, all the SMEs surveyed had implemented or were planning to implement increasing levels of automation or digital production systems 
into their manufacturing operations [68]. All of the medium-to-large SMEs (regardless of sector) had implemented automated technologies and systems within the previous 5 years. Utilization of such systems was high in that automaton was the central driver in their manufacturing processes. However, none of the automated systems were connected to their respective supply or demand chains through appropriate cyber physical systems. Therefore, the development of digitally connected supply chains was not possible and was seen by the MDs as a major limitation in those companies. Furthermore, the lack of digital connectivity affected the SMEs in the development of accurate decision-making processes. Therefore, automation and its ability to integrate the technological and managerial systems together through appropriate CPS technologies is seen as a future strategic need.

The MDs from medium/large SMEs highlighted a number of key technologies and systems that their companies intended to develop in the short-to-medium time horizon, these were as follows. Application of Time Compression and Design Technologies: the immediate utilization of time compression technologies (additive manufacturing technologies, virtual prototyping technologies etc.) to enable businesses to rapidly respond to customer and market trends and to optimize production through improved resource management and time minimization throughout the value chain $[3,70]$. Automated manufacturing systems: transitioning from traditional manufacturing systems (computer numerical control systems, semi-automated handling and conveyor systems) to higher level autonomous systems through the use of intelligent robotics and sensor systems and connected to the internet through appropriate CPSs [37]. Integrated and Connected Information and Manufacturing environments, working in real-time to enable the connectivity of multiple elements, including enhancing productivity through improving supply chain efficiency and connectivity, collaborative systems through shared design and production data, resource and material planning, and customer relationship management [68,71,72]. New skills development and greater collaboration with knowledge partners: more integrated and purposeful collaboration between knowledge and industry partners and its associated leadership that will enable the development of "digital thinking" $[73,74]$ so that SMEs manage their processes in a new way and allow for quicker and more accurate decision-making [75,76].

The respondents from the smaller manufacturing SMEs identified the need to develop knowledge and expertise of digital marketing and e-word of mouth systems (eWoM) [40-43] in order that they are able to gain greater visibility and connectivity with a wider range of customers and more immediate feedback from clients [77]. Smaller SMEs stated that SMS technologies such as the websites and social media presence needed to be developed further to include enhanced capabilities for order-making, payments, and special product requests. Key to the enhancement of SME capabilities is the need to establish strong collaborative alliances with other SMEs to reduce costs of shipping and logistics; for instance, using another company's logistics provision in order to sell one-off products and services that would otherwise be cost-prohibitive to the smaller SME.

\section{Conclusions}

The aim of this study was to obtain a greater understanding of the level of awareness and expertise of UK manufacturing SMEs towards the implementation of SMS in their companies. This study has enabled the researchers to gain a deeper understanding of the expertise and strategic priorities of manufacturing SMEs to the adoption of SMS. Through the application of the Smart Systems profiling tool that was further developed and tested in this paper and derived from previous work by Thomas et al. [3], the research team has been able to profile a range of manufacturing SMEs and to determine the strategic drivers and challenges that these companies have in the implementation of SMS. Through the use of this profiling tool and the adoption of the three-stage research approach (Figure 1), the research team has been able to identify a complex range of company strategic priorities, which indicates that SMEs require specific and individual implementation plans and systems of support going forward. 
The study specifically highlighted the need for improved support in developing more robust organizational learning systems and improved knowledge management systems in order to enable SMEs to fully exploit SMS to their maximum capabilities. The study also highlighted the need to develop greater collaboration and networks between companies and knowledge base partners so that improvements in innovation and creativity around product and process innovation is developed amongst the SMEs. This will help to prevent a culture of isolation and a disinvestment in technologies thus leading to SMEs becoming progressively less competitive. The development of stronger collaborative engineering systems forged between SMEs and universities and the further development of collaborative manufacturing networks and value chains is essential for SMEs to obtain the necessary knowledge and support structures in order to implement SMS into their respective companies. Whilst most SMEs were aware of the advantages that SMS could bring to their business, few had a detailed understanding of how SMS could be implemented and fully exploited to ensure productivity and performance improvements could be achieved.

This study further identifies that in some cases, the more progressive, smaller SMEs are focused on more proactive tools, including how SMS can successfully be used to improve efficiencies in small batch manufacturing, reducing the time for taking new products to market, and the promotion of the company on a much wider scale through the development of new and innovative products and process innovations.

Interestingly, SMEs had for some time seen the need to develop SMS as the external political and economic pressures were pushing SMEs towards the need for more advanced manufacturing and production technologies in order to achieve greater consistency of manufacturing and to meet the higher levels of customer demand for products. The usual impediments around training, staff development and knowledge management are still there in terms of SMS implementation but SMEs now see the need to overcome these issues in order to embed SMS into the business systems.

A limitation of this study is the limited sample size obtained for the survey. Whilst the total response level of thirty-six companies enabled the research team to identify a number of key themes around Smart Manufacturing Systems within manufacturing SMEs, the work cannot be considered to have statistical significance and, therefore, the outputs of the study are to be considered with this limitation in mind.

Author Contributions: Conceptualization, A.T. and P.B.; methodology, A.T.; software, M.F.; validation, W.M., C.H.-T. formal analysis, A.T.; investigation, A.T., P.B.; resources, P.B.; data curation, A.T.; writing-original draft preparation, A.T., C.H.-T.; writing-review and editing, A.T., C.H.-T.; visualization, W.M.; supervision, A.T.; project administration, A.T.; funding acquisition, A.T. All authors have read and agreed to the published version of the manuscript.

Funding: This research received no external funding.

Informed Consent Statement: Informed consent was obtained from all subjects involved in the study.

Data Availability Statement: Data available in a publicly accessible repository.

Conflicts of Interest: The authors declare no conflict of interest. 


\section{Appendix A}

Table A1. Profiling Questionnaire.

\section{Please Rate Your Company's Level of Expertise and Knowledge of the Following Technology Dimensions:}

\begin{tabular}{llllllllll}
$\begin{array}{l}\text { MD Response: (1) Little/No } \\
\text { Expertise, (5) Extensive } \\
\text { Expertise }\end{array}$ & \multicolumn{4}{l}{$\begin{array}{l}\text { Observed Response: (2) } \\
\text { Little/No Evidence, (5) } \\
\text { Extensive Evidence }\end{array}$} \\
\hline 1 & 2 & 3 & 4 & 5 & 1 & 2 & 3 & 4 & 5 \\
\hline
\end{tabular}

Customer integration with the company development process?

Application of time compression technologies

Robust New Product Development/Introduction (NPD/I)

Intelligent and Customised products

$\mathrm{R}+\mathrm{D}$ Systems/Co-Innovation/creativity

Competency management

Organisational Learning systems

Intelligent decision-making systems

Waste Reduction Systems

Energy-neutral production systems

Information Sharing Systems

Rapid Supply Chain Reconfiguration

Customer and Supply Chain Collaboration

Company/University Collaboration

Manufacturing Fitness

Technology Management Systems

Digitally Connected Supply Chains

Data analytics and Production Analytics

Table A2. Semi-Structured Interview Questions.

\begin{tabular}{cll}
\hline & \multicolumn{1}{c}{ Semi-Structured Interview Question } & Thematic Area from Table 1 \\
Q1 & $\begin{array}{l}\text { Please outline the current manufacturing strategy and highlight the } \\
\text { manufacturing pressures facing the company now and over the next 2 } \\
\text { years. }\end{array}$ & General contextualizing question \\
\hline Q2 & $\begin{array}{l}\text { Please outline the technologies and systems that your company will need } \\
\text { to invest in over the next 2 years in order to remain sustainable. }\end{array}$ & Digital technologies \\
\hline Q3 & $\begin{array}{l}\text { To what extent does your company currently exploit its manufacturing } \\
\text { capabilities? What are the barriers that limit your ability to fully exploit } \\
\text { your current technologies? }\end{array}$ & Applications and performance \\
\hline Q4 & $\begin{array}{l}\text { In what ways could your company develop and exploit its current } \\
\text { technological and systems capabilities to their fullest extent? }\end{array}$ & Applications and Management Systems \\
\hline Q5 & $\begin{array}{l}\text { What is the extent of your company's current collaborative networks and } \\
\text { what would be your plans to develop future collaborative networks. }\end{array}$ & $\begin{array}{l}\text { Management Systems and Collaborative } \\
\text { networks }\end{array}$ \\
\hline
\end{tabular}

\section{References}

1. Hill, J.; Thomas, A.; Mason-Jones, R.K.; El-Kateb, S. The implementation of a Lean Six Sigma framework to enhance operational performance in an MRO facility. Prod. Manuf. Res. 2017, 6, 26-48. [CrossRef]

2. Pham, D.T.; Adebayo-Williams, O.; Thomas, A. A framework for fit manufacturing. Int. J. Comput. Aided Eng. Technol. 2011, 3, 415. [CrossRef]

3. Thomas, A.; Haven-Tang, C.; Barton, R.; Mason-Jones, R.; Francis, M.; Byard, P. Smart Systems Implementation in UK Food Manufacturing Companies: A Sustainability Perspective. Sustainablility 2018, 10, 4693. [CrossRef]

4. Laforet, S. Effects of size, market and strategic orientation on innovation in non-high-tech manufacturing SMEs. Eur. J. Mark. 2009, 43, 188-212. [CrossRef]

5. Schroder, C.; The Challenges of Industry 4.0 for Small and Medium-Sized Enterprises. Friedrich-Ebert-Stiftung Report. 2017. Available online: https:/ /library.fes.de/pdf-files/wiso/12683.pdf (accessed on 1 March 2020).

6. Andulkar, M.; Le, D.T.; Berger, U. A multi-case study on Industry 4.0 for SME's in Brandenburg, Germany. In Proceedings of the 51st Hawaii International Conference on System Sciences, Waikoloa Village, HI, USA, 2-6 January 2018. 
7. Mittal, S.; Khan, M.A.; Romero, D.; Wuest, T. A critical review of smart manufacturing and Industry 4.0 maturity models: Implications for small and medium-sized enterprises (SMEs). J. Manuf. Syst. 2018, 49, 194-214. [CrossRef]

8. Jung, K.; Kulvatunyou, B.; Choi, S.; Brundage, M.P. An overview of a smart manufacturing system readiness assessment. In Proceedings of the International Conference on Advances in Production Management Systems, Iguassu Falls, Brazil, 3-7 September 2016; Springer: Berlin, Germany, 2016; pp. 705-712.

9. Nagy, J.; Oláh, J.; Erdei, E.; Máté, D.; Popp, J. The Role and Impact of Industry 4.0 and the Internet of Things on the Business Strategy of the Value Chain-The Case of Hungary. Sustainability 2018, 10, 3491. [CrossRef]

10. Thomas, A.; Byard, P.; Evans, R. Identifying the UK's manufacturing challenges as a benchmark for future growth. J. Manuf. Technol. Manag. 2012, 23, 142-156. [CrossRef]

11. Abazi, B. An approach to the impact of transformation from the traditional use of ICT to the Internet of Things: How smart solutions can transform SMEs. IFAC-Pap. OnLine 2016, 49, 148-151. [CrossRef]

12. Interreg North Sea Region, Growing 4.0. Industry 4.0-Opportunities and Challenges for SMEs in the North Sea Region-Desk Study, December 2018. Available online: https: / docplayer.net/123120276-Industry-4-0-opportunities-and-challenges-for-smesin-the-nort-sea-region-desk-study-december-2018.html (accessed on 1 March 2020).

13. Moeuf, A.; Pellerin, R.; Lamouri, S.; Tamayo-Giraldo, S.; Barbaray, R. The industrial management of SMEs in the era of Industry 4.0. Int. J. Prod. Res. 2018, 56, 1118-1136. [CrossRef]

14. Wang, S.; Wan, J.; Li, D.; Zhang, C. Implementing Smart Factory of Industrie 4.0: An Outlook. Int. J. Distrib. Sens. Netw. 2016, 12, 1-10. [CrossRef]

15. Tranfield, D.; Denyer, D.; Smart, P. Towards a methodology for developing evidence informed management knowledge by means of systematic review. Virtualization of food supply chains with the Smart Systems. J. Food Eng. 2016, 176, 128-136.

16. Pusavec, F.; Kramar, D.; Krajnik, P.; Kopac, J. Transitioning to sustainable production—Part II: Evaluation of sustainable machining technologies. J. Clean. Prod. 2010, 18, 1211-1221. [CrossRef]

17. De Medeiros, J.F.; Ribeiro, J.L.D.; Cortimiglia, M.N. Success factors for environmentally sustainable product innovation: A systematic literature review. J. Clean. Prod. 2014, 65, 76-86. [CrossRef]

18. Damjanovic-Behrendt, V.; Behrendt, W. An open source approach to the design and implementation of Digital Twins for Smart Manufacturing. Int. J. Comput. Integr. Manuf. 2019, 32, 366-384. [CrossRef]

19. Ding, K.; Chan, F.T.S.; Zhang, X.; Zhou, G.; Zhang, F. Defining a Digital Twin-based Cyber-Physical Production System for autonomous manufacturing in smart shop floors. Int. J. Prod. Res. 2019, 57, 6315-6334. [CrossRef]

20. Elmaraghy, W. Knowledge Management in collaborative engineering. Int. J. Collab. Eng. 2009, 1, 114. [CrossRef]

21. Manzini, E.; Vezzoli, C. A strategic design approach to develop sustainable product service systems: Examples taken from the 'environmentally friendly innovation' Italian prize. J. Clean. Prod. 2003, 11, 851-857. [CrossRef]

22. Jasiulewicz-Kaczmarek, M.; Saniuk, A. Human factor in Sustainable Manufacturing. In Universal Access in Human-Computer Interaction. Access to the Human Environment and Culture; Antona, M., Stephanidis, C., Eds.; Springer: Basel, Switzerland, 2015; Volume 9178, pp. 444-455. [CrossRef]

23. Javahernia, A.; Sunmola, F. A simulation approach to innovation deployment readiness assessment in manufacturing. Prod. Manuf. Res. 2017, 5, 81-89. [CrossRef]

24. Caputo, F.; Walletzky, L.; Štepánek, P. Towards a systems thinking based view for the governance of a smart city's ecosystem: A bridge to link Smart Technologies and Big Data. Kybernetes 2019, 48, 108-123. [CrossRef]

25. Murray, A.; Haynes, K.; Hudson, L.J. Collaborating to achieve corporate social responsibility and sustainability? Possibilities and problems. Sustain. Account. Manag. Policy J. 2010, 1, 161-177. [CrossRef]

26. Sobaszek, Ł.; Gola, A.; Świć, A. Predictive Scheduling as a Part of Intelligent Job Scheduling System. In Intelligent Systems in Production Engineering and Maintenance, Proceedings of the ISPEM 2017: First International Conference on Intelligent Systems in Production Engineering and Maintenance, Wrocław, Poland, 28-29 September 2017; Springer: Berlin, Germany, 2017; pp. 358-367.

27. Gola, A.; Kłosowski, G. Application of Fuzzy Logic and Genetic Algorithms in Automated Works Transport Organization. In Proceedings of the International Symposium on Distributed Computing and Artificial Intelligence, Toledo, Spain, 20-22 June 2018; pp. 29-36.

28. Edwards, M.G. An integrative metatheory for organisational learning and sustainability in turbulent times. Learn. Organ. 2009, 16, 189-207. [CrossRef]

29. Bahle, G.; Calma, A.; Leimeister, J.M.; Lukowicz, P.; Oeste-Reiss, S.; Reitmaier, T.; Schmidt, A.; Sick, B.; Stumme, G.; Zweig, K.A. Lifelong Learning and Collaboration of Smart Technical Systems in Open-Ended Environments-Opportunistic Collaborative Interactive Learning. In Proceedings of the 2016 IEEE International Conference on Autonomic Computing (ICAC), Wurzburg, Germany, 17-22 July 2016; pp. 315-324. [CrossRef]

30. Karagouni, G. Production technologies and low-technology knowledge-intensive venturing. EuroMed J. Bus. 2018, 13, 75-85. [CrossRef]

31. Müller, J.M. Business model innovation in small- and medium-sized enterprises: Strategies for industry 4.0 providers and users. J. Manuf. Technol. Manag. 2019, 30, 1127-1142. [CrossRef] 
32. Herrmann, C.; Blume, S.; Kurle, D.; Schmidt, C.; Thiede, S. The Positive Impact Factory-Transition from Eco-Efficiency to Eco-Effectiveness Strategies in Manufacturing. In Proceedings of the 22nd CIRP Conference on Life Cycle Engineering, Sydney, Australia, 7-9 April 2015; pp. 19-27.

33. Shrouf, F.; Ordieres, J.; Miragliotta, G. Smart factories in Industry 4.0: A review of the concept and of energy management approached in production based on the Internet of Things paradigm. In Proceedings of the 2014 IEEE International Conference on Industrial Engineering and Engineering Management, Bandar Sunway, Malaysia, 9-12 December 2014; pp. 697-701.

34. Katchasuwanmanee, K.; Bateman, R.; Cheng, K. An Integrated approach to energy efficiency in automotive manufacturing systems: Quantitative analysis and optimisation. Prod. Manuf. Res. 2017, 5, 90-98. [CrossRef]

35. Jain, V.; Benyoucef, L. Managing long supply chain networks: Some emerging issues and challenges. J. Manuf. Technol. Manag. 2008, 19, 469-496. [CrossRef]

36. Martin, C.; Towill, D.R. Supply chain migration from lean and functional to agile and customised. Supply Chain Manag. Int. J. 2000, 5, 206-213. [CrossRef]

37. Rauch, E.; Dallasega, P.; Matt, D.T. The way from Lean Product Development (LPD) to Smart Product Development (SPD). In Proceedings of the 26th CIRP Design Conference, Procedia CIRP, Stockholm, Sweden, 15-17 June 2016; Volume 50, pp. 26-31. [CrossRef]

38. Jeong, H.-J.; Koo, D.-M. Combined effects of valence and attributes of e-WOM on consumer judgment for message and product: The moderating effect of brand community type. Internet Res. 2015, 25, 2-29. [CrossRef]

39. Jalilvand, M.R.; Samiei, N. The effect of electronic word of mouth on brand image and purchase intention: An empirical study in the automobile industry in Iran. Mark. Intell. Plan. 2012, 30, 460-476. [CrossRef]

40. Yu, X.; Roy, S.K.; Quazi, A.; Nguyen, B.; Han, Y. Internet entrepreneurship and "the sharing of information" in an Internet-ofThings context: The role of interactivity, stickiness, e-satisfaction and word-of-mouth in online SMEs' websites. Internet Res. 2017, 27, 74-96. [CrossRef]

41. Abubakar, A.M.; Ilkan, M.; Sahin, P. eWOM, eReferral and gender in the virtual community. Mark. Intell. Plan. 2016, 34, 692-710. [CrossRef]

42. Habraken, M.; Bondarouk, T. Smart Industry Research in the Field of HRM: Resetting Job Design as an Example of Upcoming Challenges. In Tanya Bondarouk; Huub, J.M., Ruël, E.P., Eds.; Electronic HRM in the Smart Era (The Changing Context of Managing People, Volume); Emerald Publishing Limited: West Yorkshire, UK, 2017; pp. 221-259.

43. Sivathanu, B.; Pillai, R. Smart HR 4.0-How industry 4.0 is disrupting HR. Hum. Resour. Manag. Int. Dig. 2018, $26,7-11$. [CrossRef]

44. Ghobakhloo, M.; Fathi, M. Corporate survival in Industry 4.0 era: The enabling role of lean-digitized manufacturing. J. Manuf. Technol. Manag. 2019, 31, 1-30. [CrossRef]

45. Mittal, S.; Khan, M.A.; Romero, D.; Wuest, T. Smart manufacturing: Characteristics, technologies and enabling factors. Proc. Inst. Mech. Eng. Part B J. Eng. Manuf. 2019, 233, 1342-1361. [CrossRef]

46. Mittal, S.; Khan, M.A.; Purohit, J.K.; Menon, K.; Romero, D.; Wuest, T. A smart manufacturing adoption framework for SMEs. Int. J. Prod. Res. 2019, 58, 1555-1573. [CrossRef]

47. Agostini, L.; Nosella, A. The adoption of Industry 4.0 technologies in SMEs: Results of an international study. Manag. Decis. 2019, 58, 625-643. [CrossRef]

48. Lin, T.-C.; Wang, K.-J.; Sheng, M.L. To assess smart manufacturing readiness by maturity model: A case study on Taiwan enterprises. Int. J. Comput. Integr. Manuf. 2019, 33, 102-115. [CrossRef]

49. Zawadzki, P.; Żywicki, K. Smart Product Design and Production Control for Effective Mass Customization in the Industry 4.0 Concept. Manag. Prod. Eng. Rev. 2016, 7, 105-112. [CrossRef]

50. Zilch, A.; Schalla, P. PAC Organizes and Assesses Projects for Industrie 4.0 and the Internet of Things with New “Innovation Register". 2015. Available online: https: / / www.paconline.com/pac-organizes-and-assesses-projectsindustrie-40-and-internetthings-new-innovationregister (accessed on 1 March 2020).

51. Rahman, H.; Rahman, A. Strategic fit: Model development and fitness analysis of a manufacturing unit. Prod. Manuf. Res. 2019, 7, 44-66. [CrossRef]

52. Zheng, M.; Wu, K. Smart spare parts management systems in semiconductor manufacturing. Ind. Manag. Data Syst. 2017, 117, 754-763. [CrossRef]

53. Sony, M. Industry 4.0 and lean management: A proposed integration model and research propositions. Prod. Manuf. Res. 2018, 6 , 416-432. [CrossRef]

54. Oswald, A.; Muller, W. Management 4.0, Handbook for Agile Practices; Books on Demand: Norderstedt, Germany, 2018; ISBN 978-3746094090.

55. Shamim, S.; Cang, S.; Yu, H.; Li, Y. Management Approaches for Industry 4.0, A Human Resource Management Perspective. In Proceedings of the IEEE Congress on Evolutionary Computing, Vancouver, BC, Canada, 24-29 July 2016. [CrossRef]

56. Tu, M.; Lim, M.K.; Yang, M.-F. IoT-based production logistics and supply chain system: A framework and evaluation. Ind. Manag. Data Syst. 2018, 118, 96-125. [CrossRef]

57. Ardito, L.; Petruzzelli, A.M.; Panniello, U.; Garavelli, A.C. Towards Industry 4.0: Mapping digital technologies for supply chain management-marketing integration. Bus. Process. Manag. J. 2019, 25, 323-346. [CrossRef] 
58. Jeble, S.; Dubey, R.; Childe, S.J.; Papadopoulos, T.; Roubaud, D.; Prakash, A. Impact of big data and predictive analytics capability on supply chain sustainability. Int. J. Logist. Manag. 2018, 29, 513-538. [CrossRef]

59. Hopkins, J.; Hawking, P. Big Data Analytics and IoT in logistics: A case study. Int. J. Logist. Manag. 2018, 29, 575-591. [CrossRef]

60. Barenji, A.V.; Li, Z.; Wang, W.M.; Huang, G.Q.; Guerra-Zubiaga, D.A. Blockchain-based ubiquitous manufacturing: A secure and reliable cyber-physical system. Int. J. Prod. Res. 2020, 58, 2200-2221. [CrossRef]

61. He, W.; Xu, L. A state-of-the-art survey of cloud manufacturing. Int. J. Comput. Integr. Manuf. 2015, 28, 239-250. [CrossRef]

62. Pirola, F.; Cimini, C.; Pinto, R. Digital readiness assessment of Italian SMEs: A case-study research. J. Manuf. Technol. Manag. 2019, 31, 1045-1083. [CrossRef]

63. Bosman, L.; Hartman, N.; Sutherland, J. How manufacturing firm characteristics can influence decision making for investing in Industry 4.0 technologies. J. Manuf. Technol. Manag. 2019, 31, 1117-1141. [CrossRef]

64. Ferreira, J.; Lopes, F.; Doumeingts, G.; Sousa, J.; Mendonça, J.P.; Agostinho, C.; Jardim-Goncalves, R. Empowering SMEs with Cyber-Physical Production Systems: From Modelling a Polishing Process of Cutlery Production to CPPS Experimentation. In Intelligent Systems: Theory, Research and Innovation in Applications. Studies in Computational Intelligence; Jardim-Goncalves, R., Sgurev, V., Jotsov, V., Kacprzyk, J., Eds.; Springer: Cham, Switzerland, 2020; Volume 864.

65. Menezes, S.; Creado, S.; Zhong, R. Smart Manufacturing Execution Systems for Small and Medium-sized Enterprises. Procedia CIRP 2018, 72, 1009-1014. [CrossRef]

66. Bhatt, T.; Cusack, C.; Dent, B.; Gooch, M.; Jones, D.; Newsome, R.; Stitzinger, J.; Sylvia, G.; Zhang, J. Project to Develop an Interoperable Seafood Traceability Technology Architecture: Issues Brief. Compr. Rev. Food Sci. Food Safety 2016, 15, 392-429. [CrossRef]

67. Iqbal, J.; Khan, Z.H.; Khalid, A. Prospects of robotics in food industry. Food Sci. Technol. 2017, 37, 159-165. [CrossRef]

68. Hollmann, R.L.; Scavarda, L.F.; Thomé, A.M.T. Collaborative planning, forecasting and replenishment: A literature review. Int. J. Prod. Perform. Manag. 2015, 64, 971-993. [CrossRef]

69. Rahimifard, S.; Woolley, E.; Webb, D.P.; Garcia-Garcia, G.; Stone, J.; Jellil, A.; Gimenez-Escalante, P.; Jagtap, S.; Trollman, H. Forging New Frontiers in Sustainable Food Manufacturing; Campana, G., Ed.; Springer: Berlin, Germany, 2017.

70. Rodriguez, A.; Rodriguez, Y. Metaphors for today's leadership: VUCA world, millennial and “Cloud Leaders". J. Manag. Dev. 2015, 34, 854-866. [CrossRef]

71. Scheer, A.W. Industrie revolution 4.0 ist mit weitreichenden organisatorischen Konsequenzen verbunden! (Industrial Revolution 4.0 is associated with far-reaching organizational consequences!). Inf. Manag. Consult. 2012, 3, 10-11.

72. Roblek, V.; Meško, M.; Krapež, A. A Complex View of Industry 4.0. SAGE Open 2016, 6, 1-11. [CrossRef]

73. Hunt, I.; Wall, B.; Jadgev, H. Applying the concepts of extended products and extended enterprises to support the activities of dynamic supply networks in the agri-food industry. J. Food Eng. 2005, 70, 393-402. [CrossRef]

74. Trienekens, J.; Wognum, P.; Beulens, A.; van der Vorst, J. Transparency in complex dynamic food supply chains. Adv. Eng. Inform. 2012, 26, 55-65. [CrossRef]

75. Fassam, L.; Dani, S. A conceptual understanding of criminality and integrity challenges in food supply chains. Br. Food J. 2017, 119, 67-83. [CrossRef]

76. Garzoni, A.; de Turi, I.; Secundo, G.; del Vecchio, P. Fostering digital transformation of SMEs: A four levels approach. Manag. Decis. 2020. [CrossRef]

77. Bocken, N.; Short, S.W.; Rana, P.; Evans, S. A value mapping tool for sustainable business modelling. Corp. Gov. Int. J. Bus. Soc. 2013, 13, 482-497. [CrossRef]

78. Cagliano, R.; Caniato, F.F.A.; Worley, C.G. A pathway towards truly sustainable food supply chains: Balancing motivation, strategy, and impact. In Organizing Supply Chain Processes for Sustainable Innovation in the Agri-Food Industry; Emerald Group Publishing Limited: Bingley, UK, 2016; Volume 22, pp. 287-318.

79. Safar, L.; Sopko, J.; Slavomir, B.; Poklemba, R. Concept of SME Business Model for Industry 4.0 Environment. TEM J. 2018, 7, 626-637. [CrossRef] 